\title{
Improvement, calibration and validation of a distributed hydrological model over France
}

\author{
P. Quintana Seguí ${ }^{1}$, E. Martin ${ }^{1}$, F. Habets ${ }^{2}$, and J. Noilhan ${ }^{1}$ \\ ${ }^{1}$ CNRM-GAME (Météo-France CNRS). 42 av. G. Coriolis, 31057 Toulouse CEDEX, France \\ ${ }^{2}$ UMR Sisyphe (Université Pierre et Marie Curie CNRS), Centre de Géosciences, 35 rue St Honoré, \\ 77305 Fontainebleau, France
}

Received: 7 May 2008 - Published in Hydrol. Earth Syst. Sci. Discuss.: 11 June 2008

Revised: 30 September 2008 - Accepted: 19 January 2009 - Published: 18 February 2009

\begin{abstract}
The hydrometeorological model SAFRAN-ISBAMODCOU (SIM) computes water and energy budgets on the land surface and riverflows and the level of several aquifers at the scale of France. SIM is composed of a meteorological analysis system (SAFRAN), a land surface model (ISBA), and a hydrogeological model (MODCOU). In this study, an exponential profile of hydraulic conductivity at saturation is introduced to the model and its impact analysed. It is also studied how calibration modifies the performance of the model. A very simple method of calibration is implemented and applied to the parameters of hydraulic conductivity and subgrid runoff. The study shows that a better description of the hydraulic conductivity of the soil is important to simulate more realistic discharges. It also shows that the calibrated model is more robust than the original SIM. In fact, the calibration mainly affects the processes related to the dynamics of the flow (drainage and runoff), and the rest of relevant processes (like evaporation) remain stable. It is also proven that it is only worth introducing the new empirical parameterization of hydraulic conductivity if it is accompanied by a calibration of its parameters, otherwise the simulations can be degraded. In conclusion, it is shown that the new parameterization is necessary to obtain good simulations. Calibration is a tool that must be used to improve the performance of distributed models like SIM that have some empirical parameters.
\end{abstract}

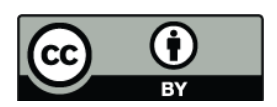

Correspondence to: P. Quintana Seguí (pere.quintana-segui@meteo.fr)

\section{Introduction}

Few distributed models are able to simulate the main land surface processes at the scale of a country like France (Henriksen et al., 2003; Mitchell and Coauthors, 2004). At this scale, many difficulties arise, which are mainly related to scale and parameterization. The SIM, model, which is used operationally at Météo-France, for example, to monitor the soil wetness index for the whole country ${ }^{1}$, is the result of the coupling of the ISBA (Noilhan and Planton, 1989; Boone et al., 1999) land surface scheme with the hydrogeological model MODCOU (Ledoux et al., 1989). The resulting model is forced by the analysis produced by SAFRAN (Durand et al., 1993; Quintana-Seguí et al., 2008).

Initially, ISBA was coupled to MODCOU with the aim to validate the land surface scheme for long periods of time and extended surfaces. The resulting model, called SIM, became a full featured hydrometeorological suite extended to the whole country. The coupling of ISBA and MODCOU showed that there was room for improvement, therefore new parameterizations were implemented to the land surface scheme with the aim of better describing processes related to hydrology. One of the consequences of these improvements was the introduction of new parameters to the model, which made its calibration more difficult. This is a difficult issue, because it is not always possible to use observations to assign the values of the parameters for such a distributed model. One way to overcome this limitation, is to use calibration. However, to avoid the problems related to overparameterization, it is important to keep the number of calibrated parameters to a minimum and to adopt a rigorous

\footnotetext{
${ }^{1}$ Maps of Soil Wetness Index produced by SIM can be found at http://www.eaufrance.fr and http://www.meteo.fr
} 
and objective parameterization procedure (Andersen et al., 2001; Refsgaard, 1997).

The objectives of this study are, 1) to review the modifications introduced to ISBA to improve its performance in the context of hydrology, 2) to improve the description of the dynamics of water in the soil, by introducing a better parameterization of hydraulic conductivity, 3 ) to calibrate the model and analyse the impact of this calibration on the performance of the model, mainly using observed riverflows.

\section{Model description}

A detailed description and validation of the SIM suite can be found at Habets et al. (2008), therefore, only its main features will be described in this paper.

\subsection{Atmospheric forcing}

SAFRAN (Durand et al., 1993; Quintana-Seguí et al., 2008) is the first element of the SIM suite. It is used to produce the analysis of near surface atmospheric parameters at a resolution of $8 \mathrm{~km}$. As input, SAFRAN uses observations from the automatic, synoptic and climatological networks of Météo-France and a first guess from a large scale operational weather prediction model. Within SIM, this first guess usually comes from the Arpge (Courtier et al., 1991) model, of Météo-France, or from the archives of the European Centre for Medium-Range Weather Forecasts (ECMWF), which is the case in this study. The analysis is made using optimal interpolation for most of the parameters. This includes, temperature and humidity (at two meters), precipitation and wind speed among others. For incoming solar radiation and downward infrared radiation, SAFRAN uses a radiative transfer scheme (Ritter and Geleyn, 1992). The analyses are performed over climatically homogeneous zones, which are areas of irregular shape covering a surface usually smaller than $1000 \mathrm{~km}^{2}$ and where the horizontal climatic gradients (specially for precipitation) are weak. SAFRAN estimates one value of each parameter for each zone at several altitude levels. Within the zone, analysed parameters depend only on elevation and aspect. However, the zones are not isolated: observations from the neighboring zones are used if necessary. A more detailed description of SAFRAN can be found in Quintana-Seguí et al. (2008).

\subsection{The ISBA land surface scheme}

ISBA (Interactions Sol Biosphère Atmosphère) (Noilhan and Planton, 1989; Boone et al., 1999) is a soil-vegetationatmosphere transfer (SVAT) scheme. It is used to simulate the exchanges in heat, mass and momentum between the continental surface (including vegetation and snow) and the atmosphere. There are several versions of ISBA, ranging from a two layer force-restore method (Deardorff, 1977), to a more detailed diffusion version (Boone, 2000; Habets et al., 2003).
SIM is implemented using the three layered force-restore version (Boone et al., 1999) with the 3-layer snow scheme of Boone and Etchevers (2001).

In the three layered version of ISBA, the evolution of the soil water content for each layer (omitting phase changes) follows these equations:

$$
\begin{aligned}
\frac{\partial w_{1}}{\partial t} & =\frac{C_{1}}{\rho_{w} d_{1}}\left(I-E_{g}\right)-D_{1} \\
\frac{\partial w_{2}}{\partial t} & =\frac{1}{\rho_{w} d_{2}}\left(I-E_{g}-E_{t r}\right)-K_{2}-D_{2} \\
\frac{\partial w_{3}}{\partial t} & =\frac{d_{2}}{d_{3}-d_{2}}\left(K_{2}+D_{2}\right)-K_{3}
\end{aligned}
$$

where $w_{i}$ are the volumetric soil water contents for each layer, $d_{i}$ are the soil depths, $\rho_{w}$ is the water density, $I$ is the infiltration (defined as the difference between precipitation and surface runoff), $E_{g}$ is the evaporation over bare ground, $E_{t r}$ is the transpiration of the vegetation, $D_{i}$ is the diffusion between each layer and, finally, $K_{i}$ is the drainage between each layer. The evolution of these two last variables is described by the following equations:

$$
\begin{aligned}
K_{2} & =\frac{C_{3}}{\tau} \frac{d_{3}}{d_{2}} \max \left[0,\left(w_{2}-w_{f c}\right)\right] \\
K_{3} & =\frac{C_{3}}{\tau} \frac{d_{3}}{d_{3}-d_{2}} \max \left[0,\left(w_{3}-w_{f c}\right)\right] \\
D_{1} & =\frac{C_{2}}{\tau}\left(w_{1}-w_{e q}\right) \\
D_{2} & =\frac{C_{4}}{\tau}\left(w_{2}-w_{3}\right)
\end{aligned}
$$

where $\tau$ is a time constant, $w_{f c}$ is the soil water content at field capacity and $w_{e q}$ is the soil water content at the equilibrium between capillarity and gravity.

The parameters $C_{1}, C_{2}, C_{3}, C_{4}$ are the force-restore coefficients. $C_{1}$ is related to the exchanges with the atmosphere, $C_{2}$ and $C_{4}$ to diffusion and $C_{3}$ to drainage. These, and the hydrological parameters of the soil (soil water contents at the wilting point $\left(w_{\text {wilt }}\right)$, field capacity $\left(w_{f c}\right)$ and saturation $\left.\left(w_{\text {sat }}\right)\right)$, are obtained a priori from the textural properties of the soil using empirical relationships (Clapp and Hornberger, 1978; Noilhan and Mahfouf, 1996; Boone et al., 1999). The theoretical equations of the $C_{i}$ parameters depend, among other variables, on hydraulic conductivity at saturation $k_{\text {sat } c}$ $\left(\mathrm{m} \mathrm{s}^{-1}\right)$, which depends on textural properties of the soil. Hydraulic conductivity is expressed as:

$k\left(w_{i}\right)=k_{\text {sat } c}\left(\frac{w_{i}}{w_{\text {sat }}}\right)^{-2 \beta+3}$

where $\beta$ is the slope of the water retention curve.

\subsection{The MODCOU hydrogeological model}

The hydrogeological model MODCOU calculates the temporal and spatial evolution of the aquifer at several layers, 
using the diffusivity equation (Ledoux et al., 1989). Then it calculates the interaction between the aquifer and the river and finally it routes the surface water to the rivers and within the river using an isochronistic algorithm. It calculates river discharge with a time step of three hours. The time step used to calculate the evolution within the aquifer is 1 day. In the version of SIM used in this study, the aquifers are only calculated in two basins: The Seine (3 layers) and the Rhône (1 layer) basins.

\section{The present state of the parameterizations of ISBA related to hydrology}

ISBA was originally designed as a simple physical model to represent the continental surface in atmospheric models. The need to validate the model over large surfaces and long periods of time, led to the coupling of the surface scheme with the hydrogeological model MODCOU (Habets, 1998). However, the first applications of the coupled system showed that it was necessary to modify ISBA to better represent processes relevant to hydrology. In the next sections, three parameterizations introduced to ISBA in the past are described and their impact to model calibration is commented.

3.1 Deep soil layer to take into account the slow hydrological component

The initial version of ISBA divided the soil in two layers: a thin superficial layer, which acted as a reservoir for evaporation from the soil surface, and a single subsurface layer to model the mean water content for the root and the subroot zones. Boone et al. (1999) divided the subsurface layer in a plant root-extration layer and a subroot layer. The new layer would dampen the amplitude of drainage pulses and increase the time lag between infiltration and drainage, making the base flow time series more realistic. A new parameter was introduced: the root depth $\left(d_{2}\right)$, which was added in addition to the total soil depth $\left(d_{3}\right)$. The values of $d_{2}$ and $d_{3}$ were set as function of the vegetation type and tested in one-dimensional and two-dimensional setups. In general, $d_{2}$ was set to be $\frac{2}{3} d_{3}$ (Habets et al., 1999b).

\subsection{Subgrid runoff scheme to simulate fast riverflow}

ISBA simulates surface runoff through the saturation excess mechanism (also known as Dune mechanism), therefore, runoff is only produced when precipitation occurs over a saturated soil. This is a problem at the scale considered in SIM, because, in reality, the scale of variability of runoff production is smaller than the typical size of the grid cell (64 $\mathrm{km}^{2}$ in our case). The consequence is that, when ISBA is run at these low resolutions, the soil almost never saturates and, therefore, there is no runoff production, even though, in reality, a fraction of the cell is saturated and does produce surface runoff. To solve this problem, a subgrid variability of runoff was introduced by Habets et al. (1999b) following the approach of the Variable Infiltration Capacity (VIC) scheme, described in Wood et al. (1992) and Dümenil and Todini (1992) and inspired from the Nanjing model (Zhao, 1992).

In this scheme, the fraction of the grid cell that is saturated is a function of some soil parameters, the soil water content of the root zone $\left(w_{2}\right)$ and a new parameter, called $b$, which represents the shape of the heterogeneity distribution of effective soil moisture capacity. To avoid too much runoff production in summer for dry soils, a threshold (wilting point) was introduced under which runoff is not produced.

In this empirical approach, the main difficulty is to set the value of the shape parameter, as it cannot be obtained a priori. This parameter could be related to subgrid topography, soil texture and vegetation type (Dümenil and Todini, 1992; Warrach et al., 2002; Decharme and Douville, 2007) but in fact, this dependency, if it exists, is not well understood and, therefore, $b$ remains a parameter to be calibrated (Xie and Yuan, 2006). In SIM, this parameter was set to a fixed value $(b=0.5)$ for almost all the cells. For sandy soils, it was set to be very small.

3.3 Subgrid drainage to implicitely take into account unresolved shallow water table

In the initial force-restore framework, drainage is produced when soil wetness is restored to field capacity $\left(w_{f c}\right)$. Therefore, when the soil is under $w_{f c}$, the model does not produce any drainage. In those places where it is known to be an aquifer which is not simulated by MODCOU, SIM underestimates the stream flows in summer, because, during this period of time, the contributions from the aquifer are the main source of water for the stream. To solve this problem, Habets et al. (1999a) introduced a parameterization which allows the existence of a residual drainage under field capacity. This residual drainage compensates the lack of contribution from the aquifer.

The parameterization, modifies the equations of ISBA for the drainage $\left(K_{3}\right)$. It introduces a new parameter $\left(w_{\text {drain }}\right)$ which needs to be calibrated in order to sustain a predefined discharge, for example, the driest observed decile $\left(Q_{10}\right)(\mathrm{Ca}-$ ballero et al., 2007; Habets et al., 2008).

This parameterization is able to improve the simulation of river discharge but, at the same time, presents two problems. First, water that should be taken from an underground aquifer, is artificially taken from the soil reservoir. Second, when the parameterization is active, the simulation of low flow is influenced by $w_{\text {drain }}$, which is calibrated, as a consequence, the model's ability to detect the impact of climate change on low flows is slightly reduced in those places where the parameterization is active.

There are two ways of improving the previous problems. The first one would be to extend the number of simulated aquifers with MODCOU. This could be done in 2-D or even 

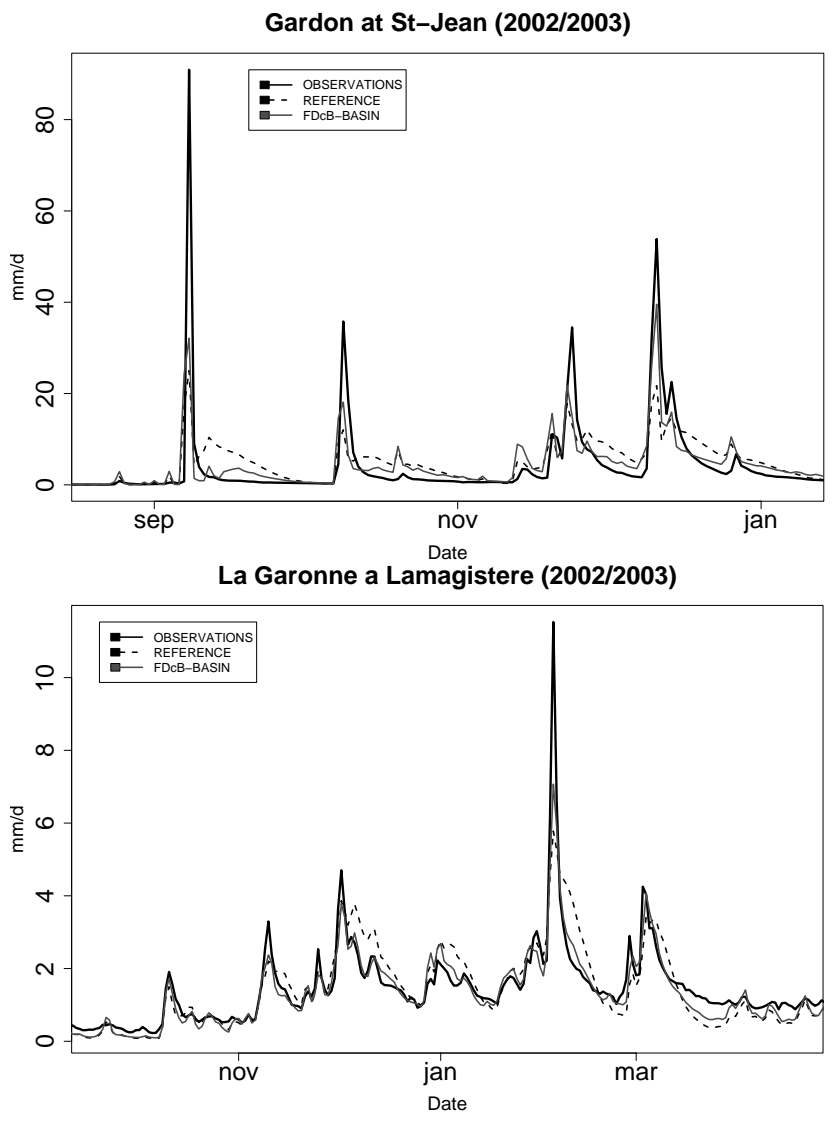

Fig. 1. Daily discharge simulated by two different versions of the SIM model on two basins for a selected period of the 2002/2003 hydrological year. The two selected basins are the Gardon at St-Jean, a small $\left(268 \mathrm{~km}^{2}\right)$ Mediterranean basin, and the Garonne at Lamagistere, a big $\left(32526 \mathrm{~km}^{2}\right)$ basin from the south west of France. The three lines of each plot correspond to the observations, the reference model, which does not include the exponential profile of saturated hydraulic conductivity, and FDcB-BASIN, which includes de exponential profile and was calibrated.

3-D for multi layer aquifers. The other possible solution would consist on introducing a 1-D representation of the aquifer, with, for example, a new reservoir, which would play the role of the non resolved aquifer (Fenicia et al., 2006). Both solutions are out of the scope of this work, nevertheless, this problem should be tackled in the future.

\section{Introducing a parameterization for hydraulic conduc- tivity in ISBA}

Even though some parameterizations were introduced into ISBA to improve its performance in the context of hydrology, at the present state, the discharges simulated by SIM present some problems, which might be due to the poor description of the dynamics of water in the soil. Figure 1 shows how SIM tends to produce a second peak of discharge just after the main events: drainage attains the river network too slowly. This shows that a better description of the processes in the soil, might help to produce a more realistic drainage and runoff, which, in turn, would help to produce more realistic discharges. In fact, preliminary sensitivity tests showed that modifications on the $C_{3}$ parameter, directly related to drainage, can lead to improvements on the simulation of river discharge. Nevertheless, the preliminary tests showed that the simple modification of this parameter is not enough, as it does not allow to improve, at the same time, peak discharge and low flow.

$C_{3}$ depends on hydraulic conductivity at saturation $\left(k_{\mathrm{sat}}\right)$. In ISBA, $k_{\text {sat }}$ depends only on soil texture (through the empirical equations of Clapp and Hornberger, 1978). As texture is constant with depth, ISBA does not consider the changes in hydraulic conductivity produced by structural causes, for example, the presence of macropores (which are produced by such agents as plant roots, soil cracks, or soil fauna Young et al., 1998). Therefore, the lack of representation of the structure of the soil, leads to a $k_{\mathrm{sat}}$ that does not depend on depth and, therefore, to a non adequate $C_{3}$.

To solve this problem, Decharme et al. (2006) introduced an exponential profile of hydraulic conductivity to a version of ISBA which used the TOPMODEL approach for runoff (following the work of Montaldo and Albertson, 2001 and Chen and Kumar, 2001) and applied it to the Rhône basin at different resolutions, showing promising results. In this study, this same parameterization was introduced to the SIM suite and, therefore, extended to the whole of France. As the details of the parameterizations can be found on Decharme et al. (2006), here only its main characteristics will be shown.

Figure 2 explains the modified hydraulic conductivity in an schematic way. In this formulation, hydraulic conductivity at saturation $\left(k_{\text {sat }}\right)$ depends on depth $(z)$ :

$k_{\mathrm{sat}}(z)=k_{\mathrm{sat} c} e^{-f\left(z-d_{c}\right)}$

where $k_{\text {satc }}$ is the compacted value of saturated hydraulic conductivity, which corresponds to the value used in Eq. (8), $f$ is a shape factor and $d_{c}$ is the compacted depth $\left(k_{\mathrm{sat}}\left(d_{c}\right)=k_{\mathrm{sat} c}\right)$. The compacted depth is the depth at which the macropores of the soil disappear and the soil becomes compacted. The equation for hydraulic conductivity (Eq. 8) is replaced by

$k\left(w_{i}, z\right)=k_{\text {sat }}(z)\left(\frac{w_{i}}{w_{\text {sat }}}\right)^{-2 \beta+3}$

The introduction of this parameterization involves a recalculation of the force-restore parameters found in Eq. (4-7), which can be analytically calculated from the old values and the parameters $f$ and $d_{c}$. The $C_{3}$ parameter, which characterizes the rate at which the water profile is restored to the field capacity, becomes different for the root zone layer and the deep layer ( $C_{3}$ becomes $C_{32}$ and $C_{33}$ respectively). 
An important consequence of using this parameterization, is that it introduces two new parameters, which cannot be obtained from primary ones. Unfortunately, it is difficult to define the physically meaningful range of $f$ and $d_{c}$. For example, Chen and Kumar (2001) used a homogeneous value of $f$ of $1.8 \mathrm{~m}^{-1}$ all over the USA. Niu and Yang (2003) and Decharme et al. (2006) used a default of $2 \mathrm{~m}^{-1}$, but during sensitivity tests, they led the parameter to be in the ranges $1-8 \mathrm{~m}^{-1}$ and $1-3 \mathrm{~m}^{-1}$ respectively. For $d_{c}$ it is easier. The hypothesis is that the changes in soil structure are due to the presence of organic mater, as roots, which create preferential paths and macropores. Therefore, the compacted depth could be somewhere not far from the root depth. After sensitivity tests, Decharme et al. (2006) found that the best values of the parameters for the Saône basin (a sub-basin situated on the north part of the Rhône basin) were $f=2$ and $d_{c}=d_{2}$, being $d_{2}$ the root depth. With these values, hydraulic conductivity at the surface of a typical soil can change by one or two orders of magnitude, which strongly changes the behavior of the modeled hydrological response.

To avoid complexity, it seems attractive to reduce the number of parameters, for example, there are other implementations of the exponential profile of hydraulic conductivity, which use only one parameter $(f)$, instead of two. For example, Stieglitz et al. (1997) used $k_{\mathrm{sat}}=k_{\mathrm{sat}}(z=0) \cdot e^{-f z}$ and Chen and Kumar (2001) used $k_{\mathrm{sat}}=k_{\mathrm{sat} c} \cdot e^{-f(z-1)}$. In this case $d_{c}$ is $1 \mathrm{~m}$, which is an arbitrary assumption. In fact, preliminary tests showed that both parameters were needed to accurately represent the dynamics of water in the soil.

From now on ISBA-KSAT or SIM-KSAT will refer to the modified versions of the model.

\subsection{Modification of the subgrid drainage scheme}

In this study, subgrid drainage was implemented as in Habets et al. (2008) but adapted to the presence of an exponential profile of hydraulic conductivity. The adaptation was necessary, because the original parameterization was created for a soil with a constant $C_{3}$, and now the values of this constant are different for each layer. The only difference between the formulation used in this study and the one described in Sect. 3.3 is that the $w_{\text {drain }}$ parameter had to be different for each layer $(l)$ due to the fact that $C_{3}$ was also different for each layer. The values of $w_{\text {drain }}$ for each layer $\left(w_{\text {drain } l}\right)$ could be calculated from the old values ( $\left.w_{\text {drain }}\right)$, so there was no need to calibrate the parameters again. The new values of the parameter for a given cell are, for each layer:

$w_{\text {drain } l}=w_{\text {drain }} \frac{C_{3}}{C_{3 l}}$

where $w_{\text {drain } l}$ and $C_{3 l}$ are the new values of $w_{\text {drain }}$ and $C_{3}$ for each layer $(l)$.

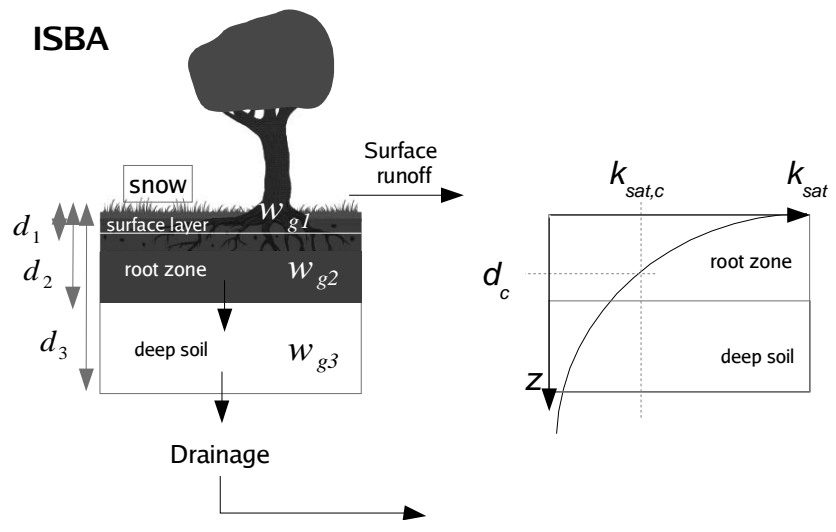

Fig. 2. Schematic description of ISBA and the exponential profile of hydraulic conductivity. Left side: The schema shows the three layers, with their corresponding water content and depths. Water leaves the system in form of evaporation, surface runoff or drainage. Right side: In ISBA hydraulic conductivity at saturation $\left(k_{\text {sat }}\right)$ is constant on the whole soil column. After introducing the exponential profile, the old constant value becomes $k_{\text {sat }}$ and $d_{c}$ is depth at which $k_{\mathrm{sat}}=k_{\mathrm{sat}}$.

\section{One-dimensional sensitivity tests}

The results shown in this section were obtained using a one dimensional version of ISBA, which included all the commented parameterizations. The data used for parameters and forcing corresponds to a ISBA grid cell situated in the south part of the Herault river basin, near the city of Montpellier, in the South of France. The soil texture of this cell is $28 \%$ clay and $35 \%$ sand, the vegetation is typically Mediterranean, with a mean root depth of $1.7 \mathrm{~m}$ and a total soil depth of $2 \mathrm{~m}$, the proportion of bare soil is of $46 \%$. For the exponential profile of hydraulic conductivity, the default values of the parameters were used. These are those found by Decharme et al. (2006): $f=2 \mathrm{~m}^{-1}$ and $d_{c}=d_{2}$. The model was run for ten years, the first year was used as a spinup, and the other nine years were used to analyse the results.

\subsection{Hydraulic conductivity}

The experiment, consisted in modifying the values of one parameter, leaving the other unmodified at its default value. The ranges of the parameters were selected according to the values used in previous studies (Sect. 4).

From the parameterizations described in previous sections, the one that affected the most the behavior of the model when it was introduced was the exponential profile of hydraulic conductivity. Changes in the force-restore coefficients, affected the soil water dynamics, soil water content, evaporation and the partition between surface runoff and drainage. For example, using the default values of the parameters, 

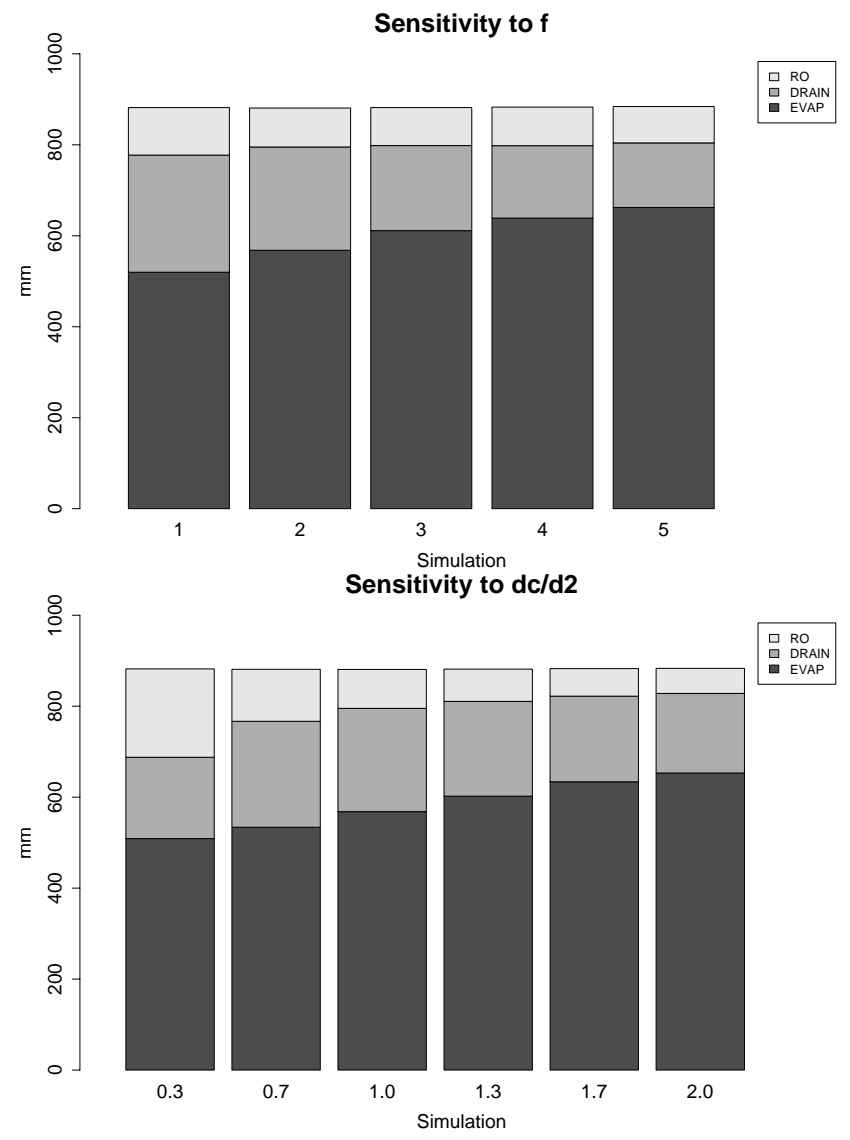

Fig. 3. Sensitivity of ISBA to the $f$ and $d_{c}$ parameters of the exponential profile of hydraulic conductivity. The model was run in 1-D over nine years. The bars show the annual mean evaporation runoff and drainage $\left(\mathrm{mm} \mathrm{y}^{-1}\right)$ for several values of the parameters. The three variables are sensitive to changes in both parameters.

which might not be realistic, ISBA-KSAT annually produced $19 \%$ more evaporation than ISBA.

The model outputs were very sensitive to changes in the values of $f$ and $d_{c}$. Figure 3 shows the sensitivity of total evaporation and the partition between surface runoff and drainage to these parameters. The main changes on evaporation were due to the changes in evaporation over bare ground, which, in the selected point, was important. The impact of both parameters on evaporation was comparable, in terms of amplitude and annual cycle, as shows Fig. 4. In fact, in both cases, the increase of the parameter increased the total evaporation, but diminished the evapotranspiration of the vegetation. The mean annual cycle of the water content of the root zone was strongly affected by $d_{c}$. The greater the value of $d_{c} / d_{2}$, the dryer the soil was. As $d_{c} / d_{2}$ increased, the annual runoff diminished, and drainage (Fig. 5) increased, attainning a maximum at $d_{c} / d_{2}=0.7$, then it diminished. On the other hand, an increase of $f$, increased drainage but left runoff and soil wetness almost constant. The cycle of evap-
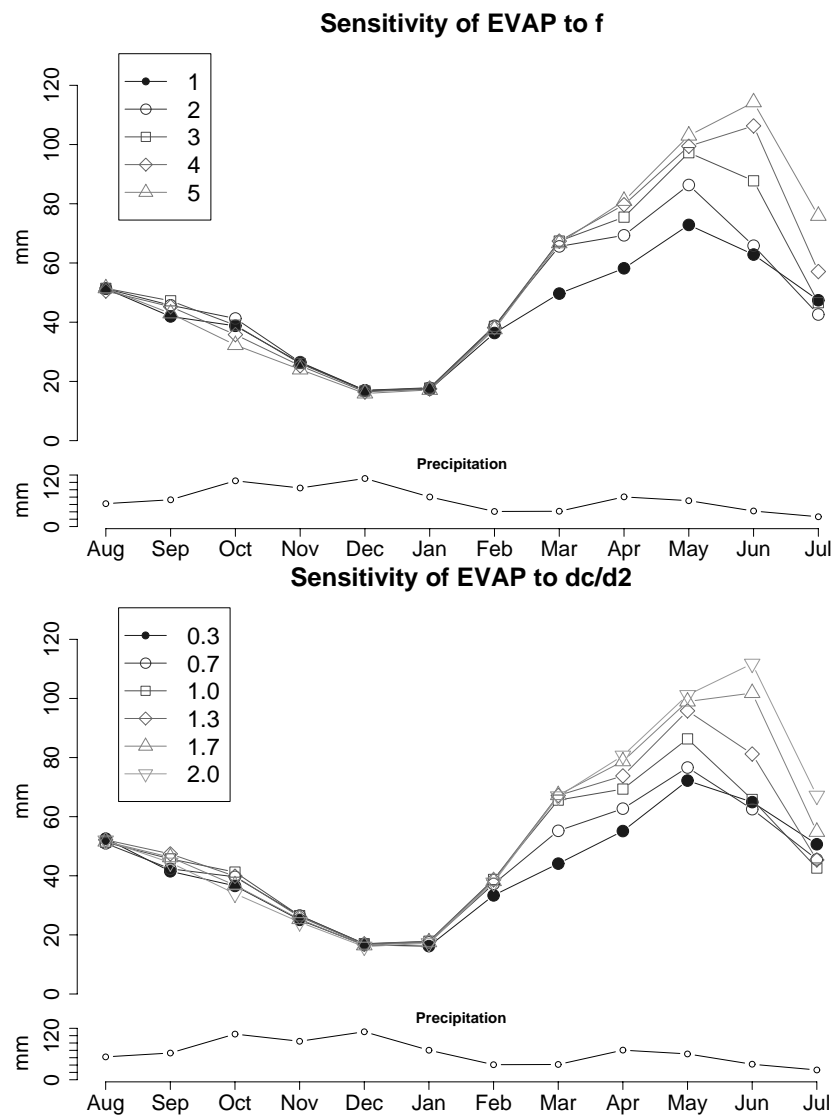

Fig. 4. Sensitivity of the annual mean cycle of evaporation (mm month ${ }^{-1}$ ) of ISBA to the $f$ and $d_{c}$ parameters of the exponential profile of hydraulic conductivity. The model was run in 1-D over nine years. The lower part of the figure shows the mean precipitation in $\mathrm{mm} \mathrm{month}^{-1}$.

oration is more sensitive during two periods: spring and autumn. The minimum is in December and August. Evaporation is more sensitive to $f$ and $d_{c}$ when it is driven mainly by processes which are related to the soil. For example, the activity of the vegetation, which pumps water from the root zone. The maximum of the vegetation is in spring. In summer (August), the activity diminishes because of soil water stress. In winter, the activity also diminishes because of the phenological cycle of the plants. For drainage, it is during maximum of the cycle that this variable is more sensitive, because during this time there is enough precipitation to fill the soil and, at the same time, evaporation is low. In this context the soil is wetter than field capacity and drainage plays a major role. This two requirements are fulfilled in winter. 

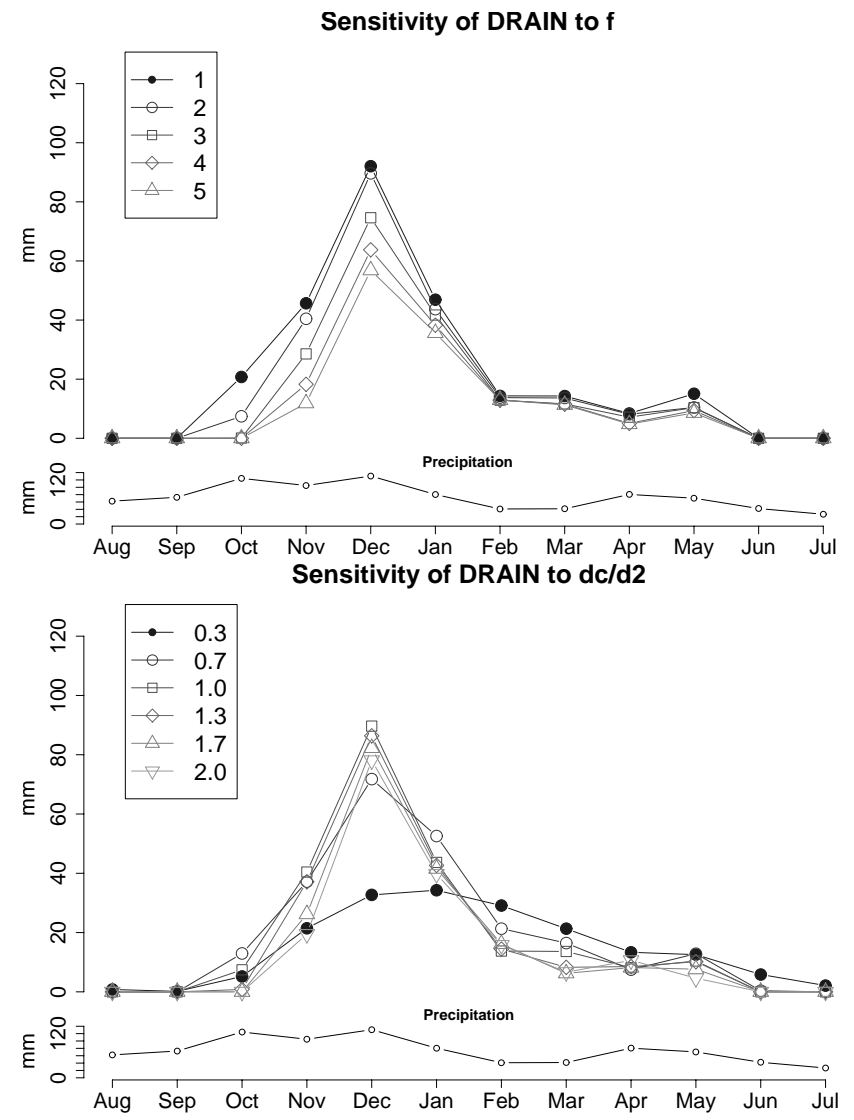

Fig. 5. Sensitivity of the annual mean cycle of drainage of ISBA to the $f$ and $d_{c}$ parameters of the exponential profile of hydraulic conductivity. The model was run in 1-D over nine years. The lower part of the figure shows the mean precipitation in $\mathrm{mm} \mathrm{month}^{-1}$.

\subsection{Subgrid runoff}

In the same fashion the values of the shape parameter of subgrid runoff were modified.

The outputs of the model were less sensitive to the shape parameter of subgrid runoff than were to the parameters related to the exponential profile of hydraulic conductivity. As expected, evaporation was not very sensitive to this parameter (Fig. 6) and it was the partition between the fast and the low components of the runoff which was mostly affected by it. As expected, the accumulated annual surface runoff was close to zero when $b$ was close to this value, as subgrid runoff is determinant for model runoff production. This is reflected in the yearly cycle of both, drainage and runoff (Fig. 7). This last variable changed considerably from almost zero in the whole period (except december), for $b=10^{-3}$ to having runoff during the whole period (in exception of July) for $b=5$. The changes of runoff are compensated by the drainage, as a consequence, the cycle of evaporation (not shown) is not very sensitive to $b$.

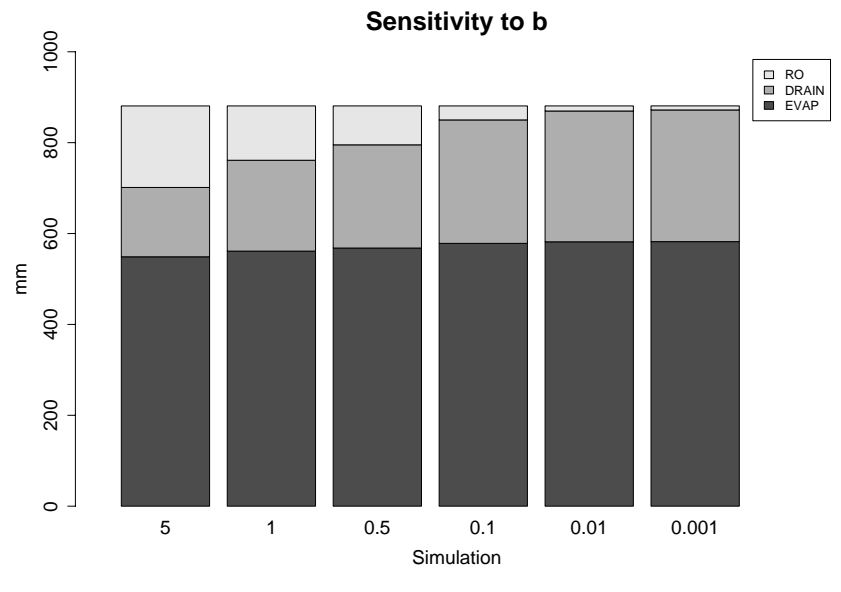

Fig. 6. Sensitivity of ISBA to the $b$ parameter of the subgrid runoff scheme. The model was run in 1-D over nine years. The bars show the mean evaporation, runoff and drainage $\left(\mathrm{mm} \mathrm{y}^{-1}\right)$ for several values of the parameters. Runoff and drainage are affected by this variable but not evaporation.

\subsection{Conclusion}

The sensitivity of ISBA to three empirical parameters, which control processes related to hydrology, was studied using a one-dimensional setup. It was found that these parameters completely control the amount of runoff and drainage produced. Evaporation was also affected considerably. Runoff was not only affected by $b$, but also by the compacted depth. This parameter, together with $f$, also strongly affected evaporation. These three parameters affect the same processes, therefore the values of one of these parameters affect the values of the others, as a result, different sets of the parameters might lead to similar results, which might lead to equifinality (Beven, 2006). This is a consequence of the empirical basis of the parameterizations. At this point, an important question arises: Which is the best way to find the appropriate values of this parameters? The next section will try to answer to this question.

\section{Calibration of the distributed model}

When using a model, like ISBA, which is intended to be as physical as possible, it is always desirable to determine the values of the parameters of the model using observed data. However, in the previous section it was seen that this is not always possible. First, because it is rare to have data for every parameter. Second, because, even though the necessary data might be accessible, it might not be directly usable due to the difference of scales between measurements and the grid of the model. Third, because, as it was seen before, some of the parameters of the model might be empirical, not physical. Therefore, in the case of facing any of the previously 

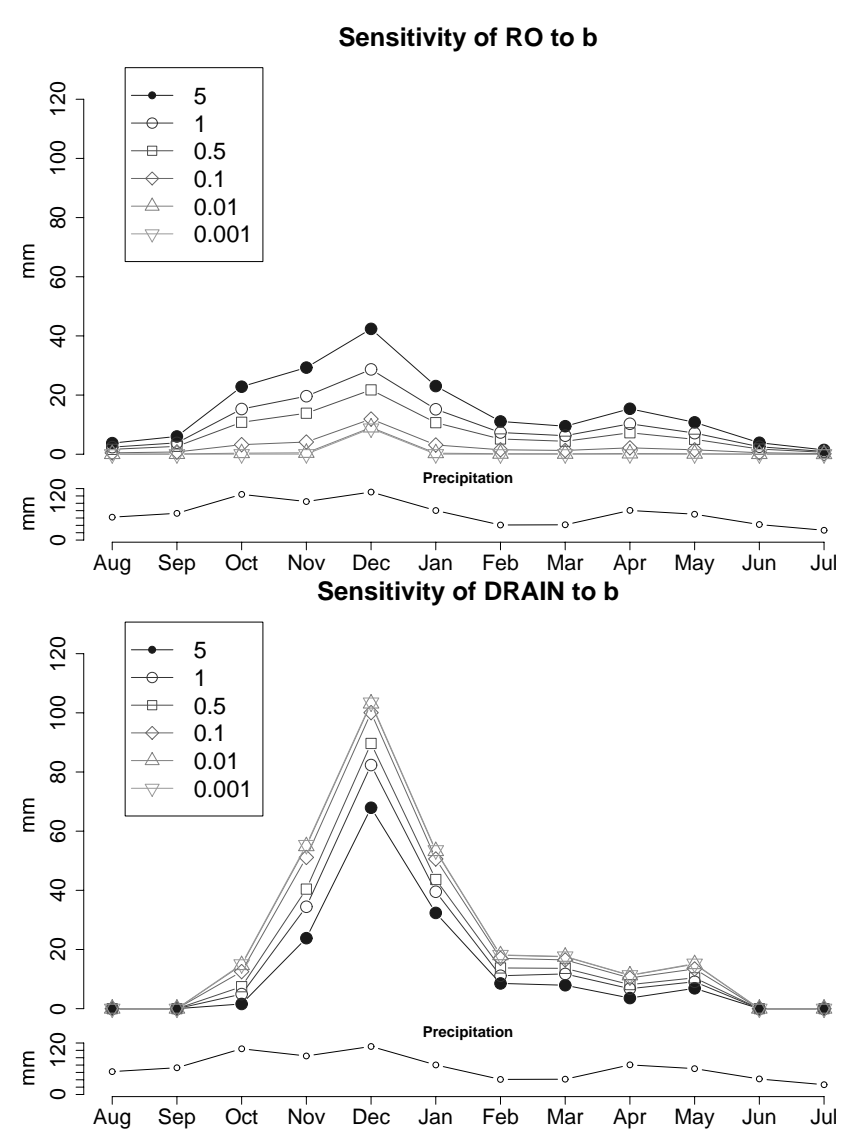

Fig. 7. Sensitivity of the annual mean cycle of runoff and drainage (mm month ${ }^{-1}$ ) of ISBA to the shape parameter of subgrid runoff. The model was run in 1-D over nine years. The lower part of the figure shows the mean precipitation in $\mathrm{mm} \mathrm{month}^{-1}$.

mentioned situations, calibration must be used. But calibration is a difficult exercise, because it can lead to obtaining good results for the wrong reasons (Kirchner, 2006). For instance, the structure of a model is always limited, as only the main processes are taken into account. Therefore, calibration can lead to situations where an existing parameterization, indirectly, takes into account processes that initially were not included in the structure of the model. This is not desirable, because it prevents the modeler to understand the behaviour of the system. In some cases, this kind of situation can be detected, for example, when the values of the calibrated parameters are out of their physical range and the model simulates the right discharges. However, sometimes there is not much information available about the physical range of the parameters, which is the case of the two parameters of the exponential profile of hydraulic conductivity at saturation (Sect. 4). But, in the context of SIM, calibration is necessary, because the physical base of the values of the parameters found in previous studies is not strong (it is the case, for example, of $b, f$ and $d_{c}$ ). Therefore, using the

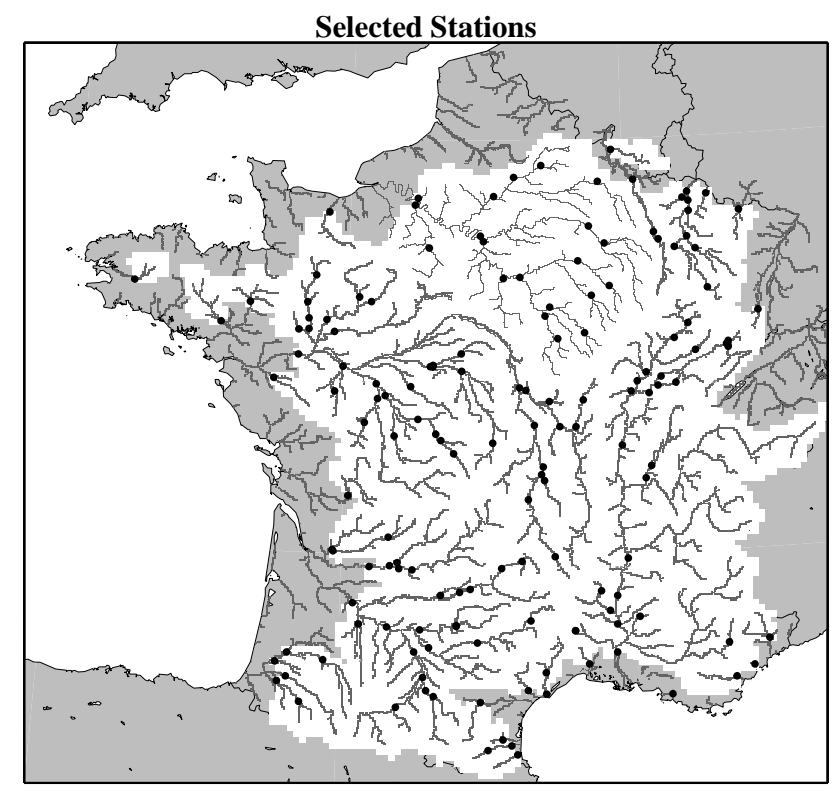

Fig. 8. Location of the 152 stations selected to calibrate and validate the model. These stations were chosen according to data availability and quality. The white region represents the ISBA grid cells $\left(8 \times 8 \mathrm{~km}^{2}\right)$ within the basins corresponding to the selected stations and, therefore, affected by the calibration. The simulated river network is depicted in gray.

values from the literature is not safer than using parameters obtained from a careful calibration.

No previous study tackled the problem of model calibration using the SIM model. Instead, a default value for each parameter was found at the time of the introduction a new parameterization. The sensitivity tests of Sec. (5) showed that the model is very dependent to the empirical parameters, therefore, it is expected that calibration will strongly improve its performance.

\subsection{Strategy of calibration}

Daily river discharge on 152 gauging stations distributed all over mainland France (Fig. 8) was used to calibrate the model. These selected stations had enough data available to calibrate and validate the model and, according to the Banque $\mathrm{Hydro}^{2}$, were not seriously affected by anthropization (for example, hydropower generation facilities). Globally, the total area covered by the catchments defined by these stations is of $432384 \mathrm{~km}^{2}$, the mean basin area is of $8227 \mathrm{~km}^{2}$, the smallest surface is of $245 \mathrm{~km}^{2}$ (Huveaune at Aubagne) and the biggest covers $110356 \mathrm{~km}^{2}$ (Loire at Montjean-sur-Loire). In general, SIM performs reasonably well on the selected stations, however the model is known to perform poorly in some basins due to structural problems.

\footnotetext{
${ }^{2} \mathrm{http}: / / w w w . h y d r o . e a u f r a n c e . f r /$
} 
For example, on the Huveaune and Argens in the South-East, which are small. These two basins were kept to test to what extend the calibration could compensate the structural problems. Furthermore, there are stations, like the Rhône at Beaucaire, which integrate the discharge of highly anthropizased tributaries, for example, the Durance which is Alpine.

Ten years of data were selected (from August 1995 to July 2005). The first five years where used to calibrate the model, the following five were used to validate it using the splitsample test technique (Klemes, 1986). Validation will be detailed in further sections.

For calibration purposes, the quality of the simulation was evaluated using a function built using the Nash-Sultcliff $(N S)$ efficiency (Nash and Sutcliffe, 1970) and the overall water balance at the daily time step, which are independent from each other (Weglarczyk, 1998). The overall water balance represents the error on the total volume which is calculated as the difference between observed and simulated runoff volumes normalised by the observed runoff. The function to minimize was:

$f\left(Q_{s}, Q_{o}\right)=(N S-1)^{2}+(W B)^{2}$

where

$N S=1-\frac{\sum_{i}\left(Q_{o_{i}}-Q_{s_{i}}\right)^{2}}{\sum_{i}\left(Q_{o_{i}}-\overline{Q_{o_{i}}}\right)^{2}}$

and

$W B=\frac{\sum_{i}\left(Q_{s_{i}}-Q_{o_{i}}\right)}{\sum_{i} Q_{o_{i}}}$

$Q_{o_{i}}$ and $Q_{s_{i}}$ are the observed and simulated river discharges at the instant $i$.

The model was calibrated gradually, from the default model, which used the default values of the parameters, to the fully calibrated model:

1. The model was run using the default values of the parameters as defined in previous studies (Habets et al., 2008; Decharme et al., 2006). This simulation was called DEFAULT.

2. $f$ and $d_{c}$ were calibrated leaving $b$ to its default value. These parameters were calibrated at two scales:

(a) The same values of the parameters were set to the whole of France (FDc-FRANCE).

(b) The values of the parameters were set at the basin scale (FDc-BASIN)

3. After the calibration of $f$ and $d_{c}$, the parameter $b$ was calibrated at the basin scale (FDcB-BASIN).

Following this strategy, the shape parameter of subgrid runoff $(b)$ was calibrated after the exponential profile of hydraulic conductivity $\left(f\right.$ and $d_{c}$ ). It would be preferable to calibrate the three parameters altogether, but such a strategy was not feasible due to the computing resources required. Therefore, it was chosen to calibrate first the parameters related to the exponential profile and then $b$. This order was chosen because, as seen in one-dimensional tests of Sect. 5, the evaporation simulated by the model is more sensitive to changes in $f$ and $d_{c}$ than on $b$. The first two parameters affect evaporation, runoff and drainage, while $b$ only affects the partition between drainage and runoff. Therefore, the calibration of $b$ was used as a fine tunning of the previous calibration. Furthermore, this allowed to test to which extent the calibration of $b$ was necessary after the introduction of the exponential profile.

\subsection{Calibration at the basin scale}

The FDc-BASIN and FDcB-BASIN simulations were calibrated at the basin scale, as opposed to FDC-FRANCE, in which each cell had the same values of the parameters. In this case, the values of each cell were identical if they belonged to the same subbasin. This calibration method is semi-distributed. As the basins defined by the selected stations are nested, a procedure was defined to decide which values would have a cell that belongs to more than one basin:

1. Each grid cell of ISBA was assigned to one single basin. If it belonged to more than one basin, because these were nested, it would assigned to the smallest.

2. Simulations were done using the same values of the parameters on the whole of France.

3. The values of the parameters assigned to each cell, were those that performed better at the station that defined the basin to which the cell belonged.

This method is very simple, but, as the results will show, it is good enough to significantly improve the results in a great number of cases keeping the number of simulations needed to do the calibration low. A better method would be to calibrate first the smallest basins, then do a new set of simulations for the cells that are not calibrated, calibrate them, and continue recursively until all the cells are calibrated. Unfortunately, such a method is too demanding in time and computational power, for such a large domain.

6.3 Finding physically meaningful ranges of the parameters

Before doing any calibration, it is crucial to find a physically meaningful range of possible values for the calibrated parameters. It must be stressed that finding a good range of values is not enough to guarantee that, after calibration, the results will be physically sound, but it remains a necessary step.

In the case of $f$ and $d_{c}$, as said in Sect. 4 , it is difficult to define this meaningful range. In Sect. 5.1, the values found on the literature were used to do one-dimensional tests. This 
Table 1. Values of the parameters chosen for the 29 simulations done to calibrate SIM-KSAT. The values of the parameters were chosen according to the corresponding values of the $C_{3}$ forcerestore parameter. $n$ is the number of stations where a set of parameters was best according to efficiency.

\begin{tabular}{cccc}
\hline Simulation & $f\left(\mathrm{~m}^{-1}\right)$ & $d_{c} / d_{2}$ & $n$ \\
\hline 01 & 0.20 & 0.00 & 1 \\
02 & 0.20 & 2.80 & 2 \\
03 & 0.20 & 6.00 & 0 \\
04 & 1.00 & 0.20 & 0 \\
05 & 1.00 & 0.80 & 0 \\
06 & 1.00 & 1.50 & 3 \\
07 & 1.00 & 2.20 & 0 \\
08 & 1.80 & 0.20 & 1 \\
09 & 2.00 & 0.60 & 3 \\
10 & 2.00 & 0.90 & 5 \\
11 & 2.00 & 1.25 & 7 \\
12 & 2.00 & 1.60 & 1 \\
13 & 2.50 & 1.30 & 4 \\
14 & 2.60 & 0.20 & 9 \\
15 & 2.70 & 0.75 & 13 \\
16 & 2.75 & 0.50 & 3 \\
17 & 2.75 & 1.00 & 14 \\
18 & 3.40 & 0.20 & 2 \\
19 & 3.50 & 0.40 & 13 \\
20 & 3.50 & 0.60 & 7 \\
21 & 3.50 & 0.80 & 16 \\
22 & 3.50 & 1.00 & 16 \\
23 & 4.00 & 0.70 & 8 \\
24 & 4.20 & 0.20 & 8 \\
25 & 4.20 & 0.55 & 8 \\
26 & 4.25 & 0.35 & 4 \\
27 & 4.80 & 0.33 & 3 \\
28 & 5.00 & 0.45 & 1 \\
29 & 5.00 & 0.60 & 1 \\
\hline
\end{tabular}

procedure was adequate to study the sensitivity of the model, but more care must be taken in order to calibrate it. For example, the hypothesis that the ranges of change of $f$ and $d_{c}$ are independent from each other might not hold. Therefore, a new strategy was defined to determine the ranges of the parameters.

First, $d_{c}$ was related to the root depth, as the structure of the soil and the presence of biomass are related (Sect. 4). The calibrated parameter was $d_{c} / d_{2}$, instead of $d_{c}$ alone.

Second, it was determined how $f$ and $d_{c} / d_{2}$ should be related. The effect of the exponential profile was introduced in the model through the force-restore parameters (Sect. 4). Instead of looking for a range of possible values of $f$ and $d_{c}$, it was the physically meaningful region of the phase space formed by the possible values of $C_{32}$ and $C_{33}$ that was determined.

The $C_{3}$ parameter characterizes the rate at which the water profile is restored to the field capacity, the greater it is, the faster drainage will be produced. To be coherent with the hypothesis that macropores and preferential paths are located near the surface, it was determined that $C_{32}>C_{3}$ and $C_{33}<C_{3}$.

The discretization of the phase space was determined by sensitivity tests using the one dimensional setup described in Sect. 5. These tests were also useful to specify the other limits of parameter space. It was decided that the pairs of $C_{32}$ and $C_{33}$ should not cause an unrealistic evaporation. The evaporation was considered unrealistic when the difference with the standard model was of approximately a $30 \%$. This choice is arbitrary, but reasonable. As a result, 29 pairs of $f$ and $d_{c} / d_{2}$ were selected (Table 1 ). The quantity of pairs was chosen to optimize the computational cost of the simulations and a good representation of the parameter space.

\subsection{Validation}

The model is said to be valid if its accuracy and predictive capability in the validation period have been proven to lay within predefined acceptable limits (Henriksen et al., 2003). As SIM is a physically based distributed model, it is is desirable to check, not only the model outputs or the variables used to calibrate it (discharge), but also, as many intermediate variables as possible. To do this, it is necessary to use as many sources of data as possible, but, unfortunately, for distributed models applied to large regions, like SIM, it is difficult to collect the necessary data to do the internal validation (Refsgaard, 1997).

In our case, the only available sources of data are river discharge, all over France, and piezometry, only for the Seine basin, as it is not yet possible to have access, for example, to distributed observations of soil wetness or evaporation. Piezometry is useful in those basins where underground water is simulated (in this study: the Seine and Rhône river basins) and discharge is the variable that is better observed. In this study, data of the 152 stations used in the calibration was used to validate it, but also, the performance on the remaining stations was analysed. Furthermore, other useful comparisons were also done. For example, the resulting evaporation of the model was compared to the evaporation of another version of SIM to detect changes in the patterns, which allowed us to better understand the behavior of the new model.

As it is common in the literature (Perrin et al., 2001; Moussa et al., 2007), a split-sample method was used to validate the simulated discharge (Klemes, 1986). The selected periods go from August 1995 to July 2000 (calibration) and from August 2000 to July 2005 (validation). According to the strategy of calibration, which produced different sets of parameters for different scales (Sect. 6.1), the tests were performed on each of the steps of the calibration.

Discharge was validated according to the Efficiency (Eq. 13) and the Water Balance (Eq. 14). To facilitate the analysis of the results, the numerical values of these two 
Table 2. Model performance criteria.

\begin{tabular}{lrr}
\hline Performance & Efficiency $(N S)$ & Water balance $(W B)$ \\
\hline Very Good & $>0.9$ & $<5 \%$ \\
Good & $0.8-0.9$ & $5 \%-10 \%$ \\
Fair & $0.7-0.8$ & $10 \%-20 \%$ \\
Poor & $<0.70$ & $>20 \%$ \\
\hline
\end{tabular}

criteria, were related to their qualitative counterparts, as presented in Table 2. The analysis of the results of the validation was done according to this table.

\section{Analysis of results}

\subsection{The reference simulation}

The reference simulation (REF) corresponds to the standard version of SIM, without the exponential profile of saturated hydraulic conductivity. This model was not subject to calibration. According to efficiency, it performed better during the second half of the 1995-2005 period (Fig. 9). This difference is an indication of limitations of the model, whose structure has difficulties to cope with the variability of the conditions in both periods. The quality of the water balance was very stable between periods, according to the criterion used (Fig. 10). Table 3 shows that, during the validation period in terms of efficiency, the performance of the model on more than half of the selected stations was poor, and it only was good at $10 \%$ of the stations. In terms of water balance, the quality of the results were good or very good in more than half of the stations. Therefore, in general, the model produced the right volume of discharge, but had more problems to reproduce the right dynamics.

\subsection{The default simulation}

After introducing the exponential profile of hydraulic conductivity to ISBA, Decharme et al. (2006) looked for default values of the parameters $f$ and $d_{c}$ with the aim to apply the model at the global scale. These default values of the parameters are $f=2 \mathrm{~m}^{-1}$ and $d_{c}=d_{2}$. A simulation, called DEFAULT, was performed using SIM-KSAT with these default values. The rest of the parameters remained at the same values as in SIM. The objective was to test if the values of the parameters found by Decharme et al. (2006) were generalizable to the rest of France and to measure the improvement introduced by SIM-KSAT in the case there is not new information about the values of the parameters.

In terms of efficiency, the default simulation was better than the reference one in some already well performing stations. The performance was good or very good on $17 \%$ of the stations, an improvement of $7 \%$. But the improvement was not generalised, on $51 \%$ of the stations the scores decreased.

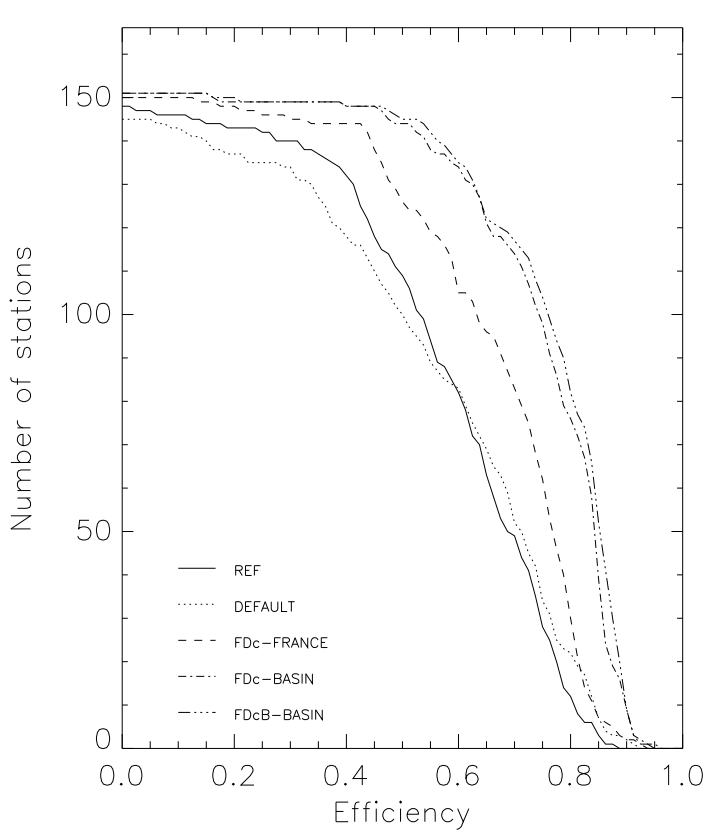

(a) Calibration Period

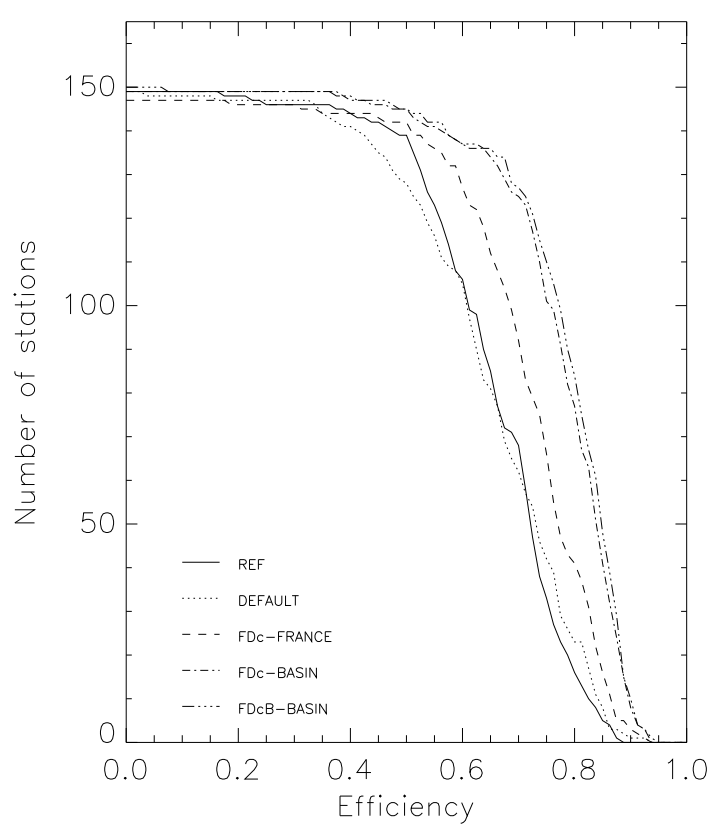

(b) Validation Period

Fig. 9. Accumulated distribution of efficiency for the 152 selected stations. Panel (a) corresponds to the calibration period (August 1995-July 2000) and panel (b) to the validation period (August 2000-July 2005). REF: standard version of SIM. All the other simulations correspond to SIM-KSAT. DEFAULT: default values of the parameters. FDc-FRANCE: calibrated values of $f$ and $d_{c}$ at the scale of France. FDc-BASIN: calibrated values of the parameters at the scale of the basin. FDcB-BASIN: As FDc-BASIN but with $b$ calibrated at the basin scale. 
Table 3. Performance, during the validation period, of the simulations on 152 selected stations, according to predefined criteria. The numbers show the percentage of the selected stations that fit in each category. REF: standard version of SIM. All the other simulations correspond to SIM-KSAT. DEFAULT: default values of the parameters. FDc-FRANCE: calibrated values of $f$ and $d_{c}$ at the scale of France. FDc-BASIN: calibrated values of the parameters at the scale of the basin. FDcB-BASIN: As FDc-BASIN but with $b$ calibrated at the basin scale.

\begin{tabular}{lccccc}
\hline \multicolumn{5}{c}{ Stations used to calibrate the model } \\
\hline & REF & DEFAULT & FDc-FRANCE & FDc-BASIN & FDcB-BASIN \\
\hline Efficiency & & & & & \\
\hline Very Good & 0 & 1 & 2 & 5 & 7 \\
Good & 10 & 16 & 25 & 45 & 49 \\
Fair & 35 & 25 & 34 & 32 & 28 \\
Poor & 54 & 59 & 39 & 18 & 16 \\
\hline Water Balance & & & & & \\
\hline Very Good & 36 & 36 & 24 & 39 & 38 \\
Good & 20 & 22 & 27 & 20 & 22 \\
Fair & 26 & 26 & 30 & 27 & 15 \\
Poor & 18 & 17 & 19 & 14 & \\
\hline
\end{tabular}

Table 4. Performance of the simulations according to predefined criteria during the validation period. The numbers show the percentage of non selected stations, out of a total of 406 , that fit in each category. Some of these stations might be seriously affected by anthropization or might lack data.

\begin{tabular}{lccccc}
\hline \multicolumn{5}{c}{ Stations not used to calibrate the model } \\
\hline & REF & DEFAULT & FDc-FRANCE & FDc-BASIN & FDcB-BASIN \\
\hline Efficiency & & & & & \\
\hline Very Good & 0 & 0 & 0 & 0 & 0 \\
Good & 2 & 5 & 7 & 14 & 14 \\
Fair & 14 & 13 & 15 & 19 & 19 \\
Poor & 84 & 81 & 77 & 66 & 66 \\
\hline Water Balance & & & & & \\
\hline Very Good & 24 & 20 & 19 & 24 & 23 \\
Good & 14 & 15 & 18 & 18 & 19 \\
Fair & 25 & 27 & 25 & 24 & 22 \\
Poor & 38 & 37 & 38 & 35 & 36 \\
\hline
\end{tabular}

The number of stations where the model performed poorly was increased $(+5 \%)$. In terms of water balance, the performance didn't change significantly. In view of this results, it is not possible to say that the introduction of the exponential profile generally improved the model. The opposite isn't true neither. Therefore, when using the exponential profile with default values of the parameters, it is difficult to say which variant of the model is the best.

\subsection{Calibration of hydraulic conductivity}

\subsubsection{The spatially uniform simulation}

The next step of the study was to improve the model by calibrating the values of the parameters related to the exponential profile of hydraulic conductivity, instead of using the default values. As a first step, the parameters were calibrated uniformly at the scale of France (FDc-France). Each cell had the same values of $f$ and $d c / d_{2}$.

As explained in Sect. 6.3, once the parameter space was delimited, 29 simulations were run using the selected values of the parameters. The third column of Table 1 shows the number of stations where each simulation was the best, in terms of efficiency. These numbers indicate that the selected range is reasonable (Sect. 6.3), as the simulations that perform better were situated in the middle of the range of $f$ and around $d_{c}=d_{2}$.

The question to answer is if there is a gain in changing the values of $f$ and $d_{c} / d_{2}$ when they are homogeneous in the 
Table 5. Comparison of the values of hydraulic conductivity at saturation ( $k_{\text {sat }}$ at the soil surface). In the REFERENCE model $k_{\text {sat }}$ is constant in the whole soil column, in FDc-BASIN, hydraulic conductivity is exponential and was calibrated. The values shown correspond to the average of the 9892 grid cells of ISBA over France.

\begin{tabular}{lrrrrr}
\hline & \multicolumn{2}{c}{$k_{\mathrm{sat}}(z=0)\left(\mathrm{m} \mathrm{s}^{-1}\right)$} & $d_{c} / d_{2}$ & $f\left(\mathrm{~m}^{-1}\right)$ \\
\hline Simulation & $\min$ & $\max$ & avg & avg & avg \\
\hline REFERENCE & $1.0 \mathrm{E}-6$ & $2.4 \mathrm{E}-4$ & $8.9 \mathrm{E}-6$ & - & - \\
FDc-BASIN & $2.9 \mathrm{E}-6$ & $1.7 \mathrm{E}-2$ & $2.7 \mathrm{E}-4$ & 0.6 & 3.1 \\
\hline
\end{tabular}

whole of France. Figure 9 and Table 3 show that, taking the simulation that had better scores in the maximum number of stations (simulation 22, $f=3 \mathrm{~m}^{-1}$ and $d_{c}=d_{2}$ ), in terms of efficiency, there was a strong gain in calibrating the model. For the validation period, almost all stations improved their scores. Comparing to DEFAULT, the number of stations with performance qualified as good or very good, in terms of efficiency, improved from $17 \%$ to $27 \%$ and the number of stations with poor results was also strongly reduced (from $56 \%$ to $39 \%$ ). Therefore, according to river discharge, the answer to the question is positive.

Comparing simulations DEFAULT and FDc-FRANCE it is deduced that the introduction of the exponential profile of hydraulic conductivity can improve the performance of the model if some adapted calibration is done, otherwise it is not guaranteed to have better results. However, to use homogeneous values of the parameters on the whole domain does not look realistic, therefore a more distributed approach could lead to better results. The objective of the next section is to test this hypothesis.

\subsubsection{The spatially heterogeneous simulation}

Once the 29 simulations of Table 1 were done, a set of parameters was found for each basin and subbasin, following the procedure described in Sect. 6.2. The resulting distribution of the parameters can be seen on Fig. 11, which reflects the values of Table 1. The figures show that, with some exceptions, the values of the parameters of neighboring basins or nested basins are similar, making large regional blocks. This coherence was expected, as in general, spatial proximity may be a good similarity measure for transposing catchment model parameters in space (Merz and Blöschl, 2004; Parajka et al., 2007). Nevertheless, there were some exceptions. Some basins had values of the parameters that contrasted with their neighbours. The causes are diverse: the basin is indeed very different to its neighbours, the quality of the observations is not good, there are several sets of the parameters that give similar results, etc. The study of such basins will be an important source of knowledge about the model and the basins themselves. The values of the parameters are coherent with those of previous studies, at the Saone
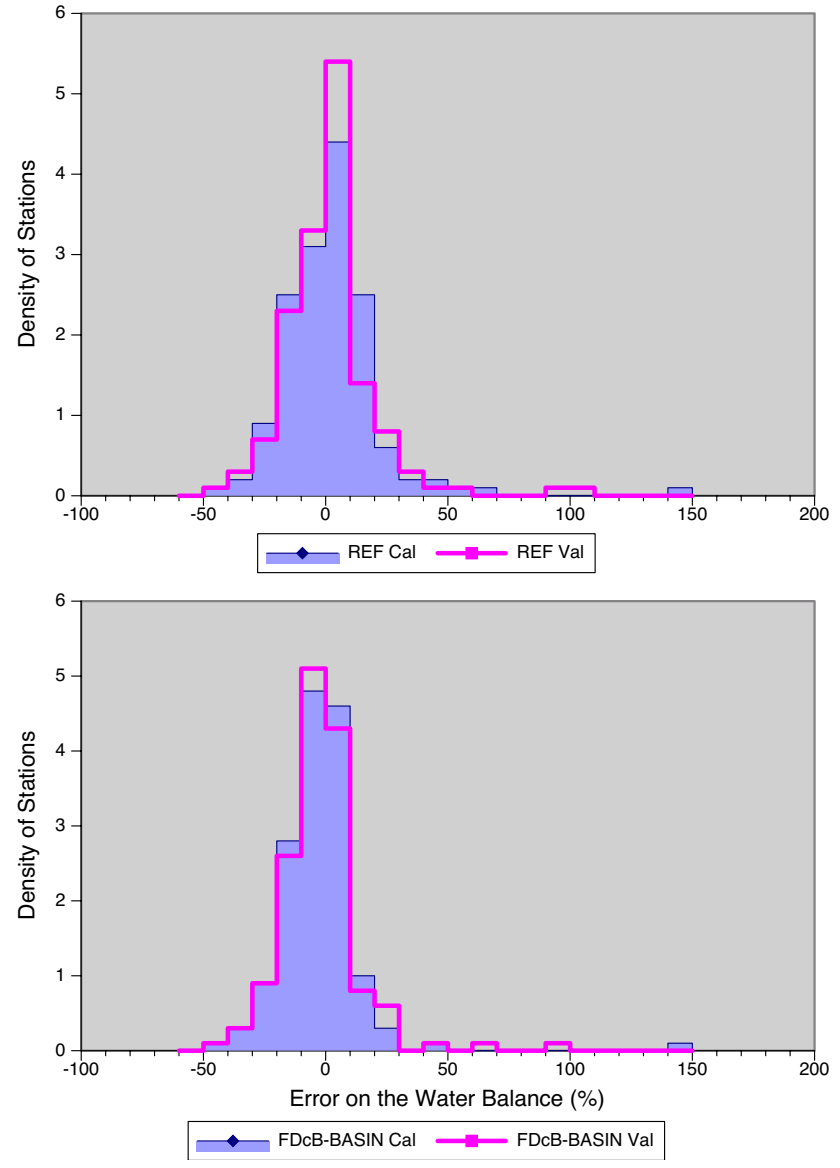

Fig. 10. Histograms of the overall water balance on the stations used to calibrate the model. The first histogram compares the SIM model (REF) for the calibration and the validation periods. The second histogram compares the performance of SIM-KSAT for the same two periods. The density of stations is the number of stations divided by the width of the bins of the histogramm $(n / 10)$. The histogram includes the results of the stations used to calibrate the model.

Basin, the best set of parameters is $f=2.5 \mathrm{~m}^{-} 1$ and $d_{c}=d_{2}$, which are very similar to those of Decharme et al. (2006) $\left(f=2.0 \mathrm{~m}^{-} 1\right.$ and $\left.d_{c}=d_{2}\right)$. Another important consequence of the introduction of the exponential profile and its calibration is that the new hydraulic conductivity at saturation changed considerably in comparison to the REFERENCE model: the average $k_{\text {sat }}$ at the surface of the soil increased in two orders of magnitude, as did the maximum (Table 5).

The results of the new simulation (FDc-BASIN) show that such an approach strongly improves the performance, both according to efficiency and total water budget (Fig. 9, Tables 3 and 4). In this case, according to Table 3, the number of stations with results qualified as good or very good, in terms of efficiency, was $50 \%$, which was a high increase comparing to the $17 \%$ of DEFAULT and the $27 \%$ of 
Table 6. Values of some important fluxes and variables for three simulations averaged on the whole of France. The values in $\%$ correspond to the relative difference with the REFERENCE simulation. $w_{2}$ is the annual mean of soil water content of the root zone and $w_{3}$ is annual mean of the soil water content of the deep layer .

\begin{tabular}{rrrrrr}
\hline Variable & REFERENCE & \multicolumn{2}{c}{ FDc-BASIN } & \multicolumn{2}{c}{ FDcB-BASIN } \\
\hline Evaporation $\left(\mathrm{mm} \mathrm{y}^{-1}\right)$ & 615 & 628 & $+2.0 \%$ & 626 & $+1.7 \%$ \\
Drainage $\left(\mathrm{mm} \mathrm{y}^{-1}\right)$ & 183 & 144 & $-21.4 \%$ & 142 & $-22.2 \%$ \\
Surface runoff $\left(\mathrm{mm} \mathrm{y}^{-1}\right)$ & 74 & 108 & $+46.3 \%$ & 111 & $+51.1 \%$ \\
$w_{2}\left(\mathrm{~m}^{3} \mathrm{~m}^{-3}\right)$ & 0.192 & 0.193 & $+0.6 \%$ & 0.193 & $+0.5 \%$ \\
$w_{3}\left(\mathrm{~m}^{3} \mathrm{~m}^{-3}\right)$ & 0.240 & 0.278 & $+15.9 \%$ & 0.277 & $+15.5 \%$ \\
\hline
\end{tabular}

FDc-FRANCE and the number of stations with poor results also diminished considerably, being $18 \%$. In terms of water balance, there was also an improvement, the results on 59\% of the stations were good or very good. This results show that there is an important gain in calibrating the model at the basin scale. Another interesting effect of the calibration is the gain in model stability. The behavior of the simulation REF in both periods, calibration and validation, was quite different (Fig. 9), being the performance better for the validation period. The calibrated model (FDc-BASIN) also did perform better during the validation period, but, interestingly, the difference in performance between both periods was lower, as opposed to the REFERENCE simulation, which was less stable across periods. Therefore, FDc-BASIN could deal with a broader range of conditions than the REFERENCE: it was more robust.

The strong change in hydraulic conductivity and the subsequent improvement in the scores of river discharge, was not accompanied by a strong change in evaporation (Table 6). In comparison to the reference model the average evaporation on France only was increased in $2 \%$. Figure 12 shows that the change on evaporation was mainly in the range $[-5 \%,-5 \%]$. Even though, in some points, the changes were more important, attaining sometimes $20 \%$. Nevertheless, as there is not distributed data available for evaporation, it is not known if this change is an improvement or it is not. On the other hand, the annual surface runoff and drainage were changed strongly. Runoff increased considerably (+46\%), which explains the more reactive discharge. Opposed to this, drainage diminished remarkably $(-21 \%)$ and the soil water content of the deepest layer increased $(+15 \%)$ as a consequence to the slower conductivity of the deep soil.

\subsection{Calibration of subgrid runoff}

In this last step, the parameter $b$ of the subgrid runoff scheme was calibrated. The previous calibration adjusted the dynamics of water in the soil, this calibration was done to find a better partition between surface runoff and drainage. In this case, 6 simulations were performed with the following values of the parameter: $b=10^{-3}, 10^{-2}, 10^{-1}, 5 \cdot 10^{-1}, 1,1.5$. This is based on the range of parameters found by Habets
(1998) in the literature. The method to assign a value to each grid cell was exactly the same as in FDc-BASIN.

The obtained values of $b$ are around 0.5 , which is the default value used in SIM, and are, with few exceptions in the range $0.1 \leq b \leq 1$. The resulting geographical distribution of the calibrated parameter presented geographical coherence. The default value of $b=0.5$ was kept in a region of the north and the center of France. For example, the Seine and the Loire basins had, mainly, a value of 0.5 . In the south western part of France, in the Adour and Garonne basins, the calibrated value was $b=1$. These geographical patterns give some confidence on the validity of the calibration procedure, but unfortunately, the values themselves are not yet understood.

Figure 9 and Table 3 show that, in terms of efficiency, this calibration helps to improve a little bit more the results. After calibrating $b, 56 \%$ of the stations were in the range of Good and Very Good efficiencies, which represents an improvement of $6 \%$. In terms of water balance, there were few changes, as expected.

Concerning the annual water balance, the results of this simulation are quite similar to the previous one, the difference on the global mean is only of $1 \%$ on terms of drainage and runoff and the differences are even lower for the soil water content. Figure 10 compares the overall water balance for this simulation on the stations used to calibrate the model. It is shown that this simulation is more stable across periods, as the two superposed histograms are more similar than the two histograms of the reference, which is a sign of robustness. Nevertheless, these results do not explain the whole change, in fact, the small difference in the mean is due to the fact that the most part of the cells kept the default value of the parameter $(b=0.5)$ and those that were different compensated each other. In fact, in the basins were the $b$ was increased to 1 , runoff increased (in comparison to the previous simulation) by around a $40 \%$ and in the basins were it was diminished to 0.1 the decrease of runoff attained values by around $-60 \%$. These strong changes in runoff didn't cause changes in evaporation, as it remain very similar to that of the previous simulation (the highest differences were by around 5\%).

In the part of the Seine basin that was calibrated, the calibration did not strongly modify the drainage, and thus, the 

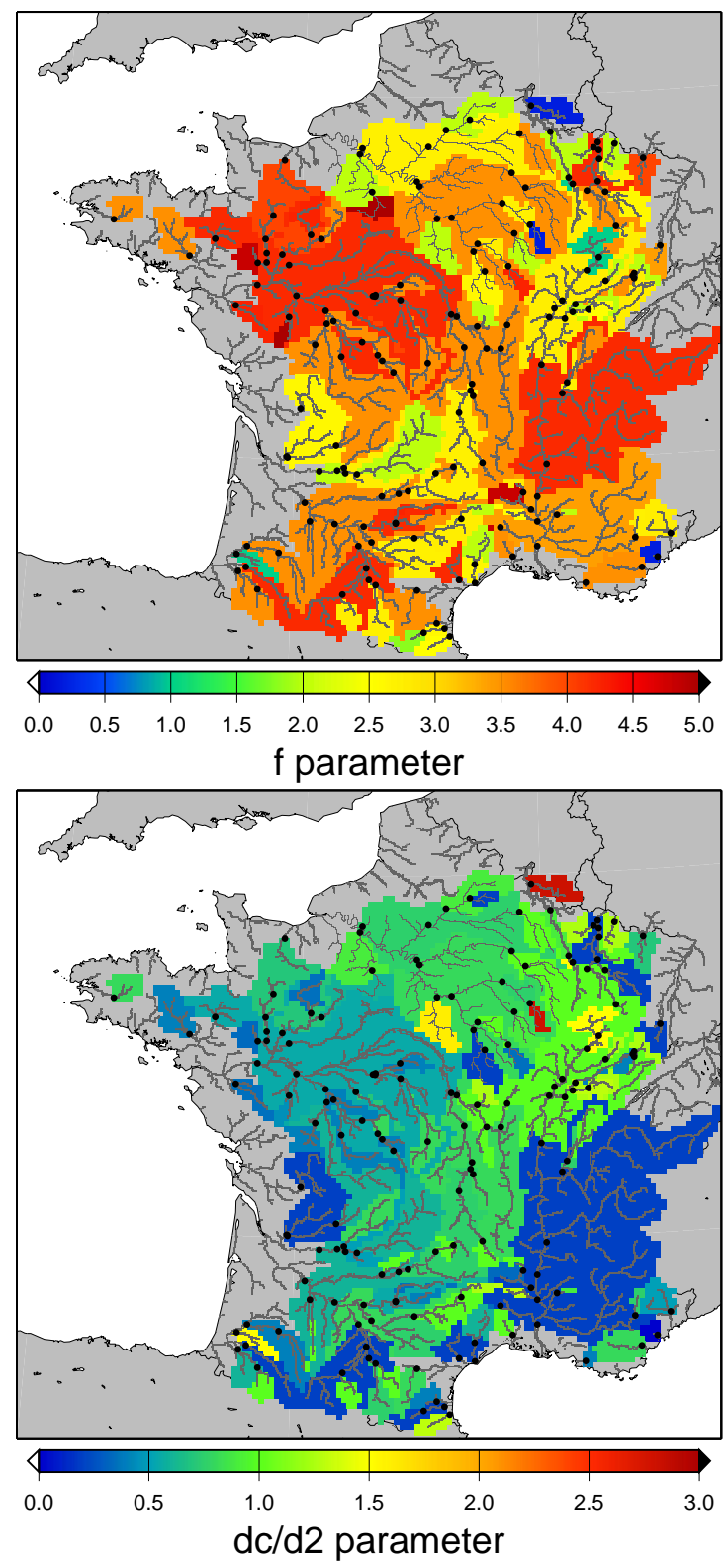

Fig. 11. Resulting geographical distribution of the values of the two parameters related to the exponential profile of hydraulic conductivity $\left(f\left(\mathrm{~m}^{-1}\right)\right.$ and the ratio between the compacted depth $\left(d_{c}\right.$ $(\mathrm{m}))$ and the root depth $\left(d_{2}(\mathrm{~m})\right)$. Colored grid cells were calibrated, the gray ones weren't, because they do not correspond to any of the basins of the selected stations, which correspond to the black dots. The simulated river network is shown in darker gray.

recharge flux to the aquifers, and the piezometry. On the three layers (oligocene, eocene and chalk aquifers) of this basin, the root mean square error (RMSE) and the bias of FDcB-BASIN remained comparable to those of the REFERENCE : the number of gages with an absolute bias lower than $2 \mathrm{~m}$ increased from 12 , in the REFERENCE simulation,
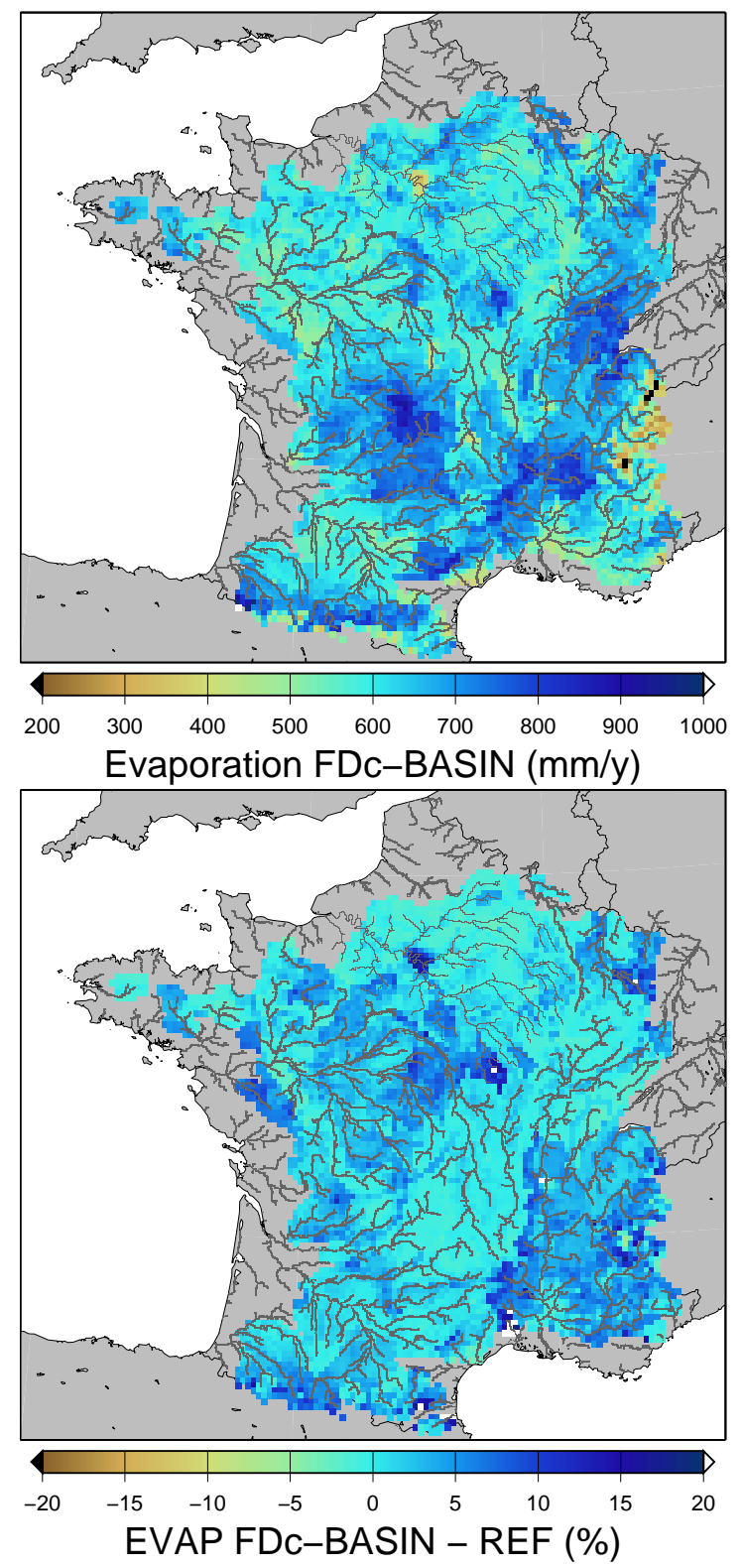

Fig. 12. Simulated geographical distribution of evaporation for the hydrological year 2001/02. Panel (a) evaporation simulated after calibrating the two parameters related to hydraulic conductivity (simulation FDc-BASIN). Panel (b) Relative difference between FDc-BASIN and the reference simulation (REF).

to 16 , in FDcB-BASIN, out of a total of 44 gages. On the contrary, in the southern half of the Rhône basin, the calibration lead to a large decrease of the drainage flux, and thus the piezometric levels showed a net decrease ( $-9 \mathrm{~m}$ on average). This is due to the fact that this part of the basin is severely affected by the anthropization of alpine tributaries. Therefore, the results of the calibration in this area must be taken with care. 

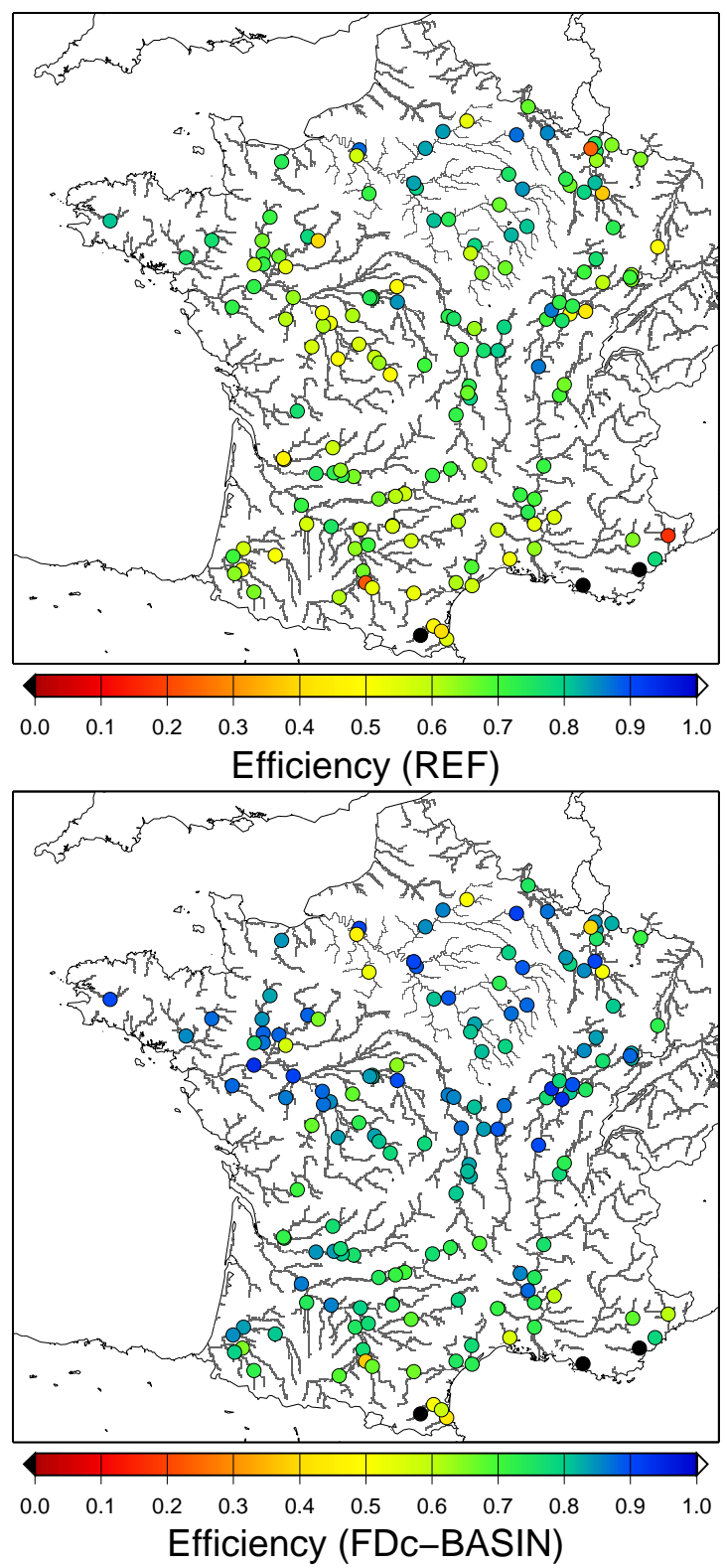

Fig. 13. Geographical distribution of the efficiency values of the 152 selected stations during the period of validation (August 2000 July 2005). The first map (REF) corresponds to the standard version of SIM (without the exponential profile of hydraulic conductivity and without calibration). The second map (FDcB-BASIN) corresponds to SIM-KSAT after calibrating the parameters related to the exponential profile of hydraulic conductivity and the runoff subgrid scheme. The simulated river network is shown in darker gray.

\section{Discussion}

The objective of this study was to improve the overall performance of the model, being its main defects related to the dynamics of the flow. Preliminary tests showed that the simple calibration of the $C_{3}$ parameter was not enough to improve the discharge (Sect. 4) and a previous study (Decharme et al., 2006) showed that the modification of the description of the hydraulic conductivity in the model offered a great potential of improvement.

The new parameterisation of hydraulic conductivity was introduced to the model and its parameters were calibrated. The results showed that the strategy is adequate. For example, if the $C_{3}$ parameter of ISBA is directly calibrated, the efficiency of the model on the Hérault at Gignac improved from 0.52 to 0.54 , on the other hand, the calibrated ISBAKSAT had an efficiency of 0.69. At the scale of France, it was shown that the simple method used to calibrate ISBA-KSAT highly improves the scores of river discharge and leaves other variables, like evaporation or the piezometric levels (at the Seine basin), almost untouched. The maps on Fig. 13 and the new discharges of Fig. 1 make explicit the overall improvement of the description of the processes related to the simulation of river discharge. Table 4 indicates that this improvement is not an artifact of the calibration, as the results on stations not used in the calibration were also improved. It was worthwhile to add some complexity to the model since both the introduction of the parameterization and the calibration were adequate to improve the SIM model as shown by the general improvement of the simulated riverflows (Fig. 1)

Nevertheless, in some basins, the parameters found by the calibration must be taken with caution. First, the method used to assign a set of parameters to each cell was very simple. As can be seen in Fig. 11, the algorithm used to decide to which basin belongs each cell produced some artifacts at the borders of some basins. Furthermore, the model cannot perform well in places were processes not simulated by the model are important, as in karstic areas or basins where anthropization is intense, for example, the Alpine part of the Rhône basin, where hydro-power production has completely changed the behaviour of a number of basins. However, it is worth noting that the calibration did not mask these effects, for example, the three basins depicted in black on Fig. 13 remain black after calibration. This means that where the model was wrong, due to structural or external reasons, it remains wrong after calibration.

The main hydrological fluxes of ISBA-KSAT, runoff and drainage, are mainly driven by empirical parameters $\left(f, d_{c}\right.$ and $b$ ). The question is how physical is such a model. ISBA is not used only in hydrology, it has a larger scope, as a consequence, it can be regarded a simple physical surface model whose hydrological processes are described by parameterisations which are conceptual to a certain degree. This degree of conceptualisation is necessary because (1), due to the resolution of the model, runoff must be described at the subgrid scale and (2) the lack of observed data and the computational restrictions do not allow a detailed description of the structure of the soil. In this context, it is appropriate to use a simple exponential profile applied to a soil described with only three layers 
Another question that arises, is what parameters should be assigned to the cells that do not belong to any of the calibration basins. This is the case for most of the coastal cells that are depicted in gray in the figures of this paper. This is important, because some stations included in Table 4 are located in these areas. FDc-FRANCE showed that there is a gain in calibrating the model homogeneously over the whole of France. This has been the strategy used in this study, but, as Parajka et al. (2007) suggest, it might also be interesting to set the values according to the nearest calibrated cell. root depth. This way, the distributed nature of the model remains intact.

The model was calibrated at the basin scale, but the hydraulic conductivity remains distributed. The original hydraulic conductivity $\left(k_{\mathrm{sat}}\right)$ was a function of soil texture, and this remains valid. In addition, the use of $d_{c} / d_{2}$ for the calibration, takes into account the variability of root depth, which depends on the variability of vegetation.

Another important question is how these calibrated parameters reflect the real properties of the basins. As the model is constructed, the values of some parameters are related to the values of other parameters. For example, $f$ and $d_{c}$ are not independent, and $b$ would be different if it was calibrated before the former parameters. Furthermore, it was chosen not to calibrate other parameters of the model, like the soil depth or some properties of the vegetation. Nevertheless, it was seen that the calibration affected the processes it intended to modify (runoff and drainage) and the scores of discharges were improved considerably. Therefore, even though it is known that this set of parameters is not the only one that would give similar results, the resulting model is realistic enough to simulate, in an appropriate manner, the relevant processes of the basin. Therefore, within the ranges defined by Table 2, the model can be defined as realistic.

Finally, the model was improved, by introducing the exponential profile of hydraulic conductivity, but the subgrid drainage remains unchanged, even though it was said it should be substituted by a new parameterisation. It might be argued that the improvement of subgrid drainage should be done before introducing the exponential profile of hydraulic conductivity. Nevertheless, the parameterisation of subgrid drainage only plays a role in those basins where there is an aquifer that is not simulated by MODCOU. This limits the scope of the parameterisation. Furthermore, subgrid drainage is mainly relevant for low flows, which further reduces the scope of the parameterisation. On the other hand, the improvement of the description of hydraulic conductivity is important everywhere, independently of the presence or not of an aquifer. For example, results improved in the Seine basin where subgrid drainage is not used at all. As a consequence, the improvement of hydraulic conductivity, has wider consequences than the improvement of subgrid drainage.

\section{Conclusions}

This study describes the modifications that were implemented on the SIM model to improve its performance in the context of hydrology. Emphasis was placed on the role of the new parameters introduced. The study showed that the new description of the hydraulic conductivity of the soil was important to produce more realistic discharges, even though some complexity was added to the model.

The new parameterization introduced includes new parameters, which have an empirical nature. As it was not possible to set the values of these parameters from direct observations, a calibration procedure was set up. It was shown that the calibration improved considerably the results and that the final model was more robust than the original SIM. The calibration mainly affected the processes it was intended to modify (drainage and runoff), and the other variables remained stable. It was also demonstrated that it is worth introducing this new empirical parameterization, only if it is accompanied by a calibration of the parameters. In conclusion, in this case, calibration is a tool that can considerably improve the performance of distributed models like SIM.

Some key issues must be further investigated. For instance, three parameters were calibrated in this study. It should be explored if more parameters should or could be also calibrated. For example, there are parameters which could be set using observed data, but, due to the lack of observations, are set to a fixed value. For example, root depth $\left(d_{2}\right)$ is usually set to be $2 / 3$ of soil depth. The soil depth is also subject to similar problems. Maybe, the calibration of parameters which suffer the same problems as $d_{2}$ and $d_{3}$ would improve the results. But adding degrees of freedom to the calibration is not necessarily good. Furthermore, the study of the interaction between parameters could help to simplify the model. Another important issue is the improvement of the method used to calibrate the model. The method used was very simple, even simplistic, and it could be improved in the future. Nevertheless, it showed to be robust enough and considerably improved the performance of the model. Finally, the study of the basins where the calibration set surprising values of the parameters, will be very useful to learn more about these basins and the behaviour of the model. This new version of the model, will be used to follow the evolution of soil wetness, the forecast of river discharge and, finally, to study the impact of climate change on the continental water cycle.

Acknowledgements. The authors are grateful to Bertrand Decharme for the useful discussions related to this article and his previous work, which made this study possible. They also are grateful to the anonymous reviewers who, with their comments, helped to improve the quality of the article. This work was partly supported by the program ACI-FNS "Aléas et Changements Globaux" of the French research ministry under the project CYPRIM. Discharge 
observations were provided by the French Hydro database (Minisère de l'Ecologie et du Développement Durable, Direction de l'Eau, http://www.eaufrance.fr), which gathers data from many producers.

Edited by: E. Zehe

\section{References}

Andersen, J., Refsgaard, J. C., and Jensen, K. H.: Distributed hydrological modelling of the Senegal River Basin - model construction and validation, J. Hydrol., 247, 200-214, 2001.

Beven, K.: A manifesto for the equifinality thesis, J. Hydrol., 320, 18-36, 2006.

Boone, A.: Modélisation des processus hydrologiques dans le schéma de surface ISBA: Inclusion d'un réservoir hydrologique, du gel et modélisation de la neige., Ph.D. thesis, Université Paul Sabatier (Toulouse III), 2000.

Boone, A. and Etchevers, P.: An Intercomparison of Three Snow Schemes of Varying Complexity Coupled to the Same Land Surface Model: Local-Scale Evaluation at an Alpine Site, J. Hydrometeorol, 2, 374-394, 2001.

Boone, A., Calvet, J. C., and Noilhan, J.: Inclusion of a Third Soil Layer in a Land Surface Scheme Using the Force-Restore Method, J. Appl. Meteorol., 38, 1611-1630, 1999.

Caballero, Y., Voirin-Morel, S., Habets, F., Noilhan, J., LeMoigne, P., Lehenaff, A., and Boone, A.: Hydrological sensitivity of the Adour-Garonne river basin to climate change, Water. Resour. Res., 43, W07448, doi:10.1029/2005WR004192, 2007.

Chen, J. and Kumar, P.: Topographic Influence on the Seasonal and Interannual Variation of Water and Energy Balance of Basins in North America, J. Climate, 14, 1989-2014, 2001.

Clapp, R. B. and Hornberger, G. M.: Empirical Equations for Some Soil Hydraulic Properties, Water. Resour. Res., 14, 601-604, 1978.

Courtier, P., Freydier, C., Geleyn, J. F., Rabier, F., and Rochas, M.: The Arpège project at Météo-France, Reading, European Centre for Medium-range Weather Forecast, 193-232, 1991.

Deardorff, J. W.: A Parameterization of Ground-Surface Moisture Content for Use in Atmospheric Prediction Models, J. Appl. Meteor., 16, 1182-1185, 1977.

Decharme and Douville: Global validation of the ISBA sub-grid hydrology, Clim. Dynam., 29, 21-37, 2007.

Decharme, B., Douville, H., Boone, A., Habets, F., and Noilhan, J.: Impact of an Exponential Profile of saturated Hydraulic Conductivity within the ISBA LSM: Simulations over the Rhône Basin, J. Hydrometeorol, 7, 61-80, 2006.

Dümenil, L. and Todini, E.: A rainfall-runoff scheme for use in the Hamburg climate model., p. 462, McGraw Hil, New York, 1992.

Durand, Y., Brun, E., Mérindol, L., Guyomarc'h, G., Lesaffre, B., and Martin, E.: A meteorological estimation of relevant parameters for snow models, Ann. Glaciol., 18, 65-71, 1993.

Fenicia, F., Savenije, H. H. G., Matgen, P., and Pfister, L.: Is the groundwater reservoir linear? Learning from data in hydrological modelling, Hydrol. Earth Syst. Sci., 10, 139-150, 2006, http://www.hydrol-earth-syst-sci.net/10/139/2006/.

Habets, F.: Modélisation du cycle continental de l'eau à l'échelle régionale. Application aux bassins versants de l'Adour et du
Rhône., Ph.D. thesis, Université Paul Sabatier (Toulouse III), 1998.

Habets, F., Etchevers, P., Golaz, C., Leblois, E., Ledoux, E., Martin, E., Noilhan, J., and Ottle, C.: Simulation of the water budget and the river flows of the Rhône basin, J. Geophys. Res., 104, 31145 31172, 1999a.

Habets, F., Noilhan, J., Golaz, C., Goutorbe, J. P., Lacarrere, P., Leblois, E., Ledoux, E., Martin, E., Ottle, C., and Vidal-Madjar, D.: The ISBA surface scheme in a macroscale hydrological model applied to the Hapex-Mobilhy area. Part I: Model and database, J. Hydrol., 217, 75-96, 1999 b.

Habets, F., Boone, A., and Noilhan, J.: Simulation of a Scandinavian basin using the diffusion transfer version of ISBA, Glob. Plant. Change, 38, 137-149, 2003.

Habets, F., Boone, A., Champeaux, J. L., Etchevers, P., Franchistéguy, L., Leblois, E., Ledoux, E., Le Moigne, P., Martin, E., Morel, S., Noilhan, J., Quintana-Seguí, P., Rousset-Regimbeau, F., and Viennot, P.: The SAFRAN-ISBA-MODCOU hydrometeorological model applied over France, J. Geophys. Res., 113, D06113, doi:10.1029/2007JD008548, 2008.

Henriksen, H. J., Troldborg, L., Nyegaard, P., Sonnenborg, T. O., Refsgaard, J. C., and Madsen, B.: Methodology for construction, calibration and validation of a national hydrological model for Denmark, J. Hydrol., 280, 52-71, 2003.

Kirchner, J. W.: Getting the right answers for the right reasons: Linking measurements, analyses, and models to advance the science of hydrology, Water. Resour. Res., 42, W03S04, doi:10.1029/2005WR004362, 2006.

Klemes, V.: Operational testing of hydrological simulation models, Hydrol. Sci. J., 31, 13-24, 1986.

Ledoux, E., Girard, G., de Marsilly, G., and Deschenes, J.: Spatially distributed modeling: conceptual approach, coupling surface water and ground water, 435-454, Kluwer Academic, Dordrecht, 1989.

Merz, R. and Blöschl, G.: Regionalisation of catchment model parameters, J. Hydrol., 287, 95-123, 2004.

Mitchell, K. E. and Coauthors: The multi-institution North American Land Data Assimilation System (NLDAS): Utilizing multiple GCIP products and partners in a continental distributed hydrological modeling system, J. Geophys. Res., 109, DE07S90, doi:10.1029/2003JD003823, 2004.

Montaldo, N. and Albertson, J. D.: On the Use of the Force-Restore SVAT Model Formulation for Stratified Soils, J. Hydrometeorol., 2, 571-578, 2001

Moussa, R., Chahinian, N., and Bocquillon, C.: Distributed hydrological modelling of a Mediterranean mountainous catchment - Model construction and multi-site validation, J. Hydrol., 337, 35-51, 2007.

Nash, J. and Sutcliffe, J.: River flow forecasting through conceptual models. Part I: A discussion of principles, J. Hydrol., 10, 282 290, 1970.

Niu, G. Y. and Yang, Z. L.: The versatile integrator of surface atmospheric processes. Part 2: Evaluation of three topography-based runoff schemes, Glob. Planet. Change, 38, 191-120, 2003.

Noilhan, J. and Mahfouf, J.: The ISBA land surface parameterisation scheme, Global Planet. Change, 13, 145-159, 1996.

Noilhan, J. and Planton, S.: A Simple Parameterization of Land Surface Processes for Meteorological Models, Mon. Weather Rev., 117, 536-549, 1989. 
Parajka, J., Blöschl, G., and Merz, R.: Regional calibration of catchment models: Potential for ungauged catchments, Water. Resour. Res., 43, W06406, doi:10.1029/2006WR005271, 2007.

Perrin, C., Michel, C., and Andreassian, V.: Does a large number of parameters enhance model performance?: Comparative assessment of common catchment model structures on 429 catchments, J. Hydrol., 242, 275-301, 2001.

Quintana-Seguí, P., Moigne, P. L., Durand, Y., Martin, E., Habets, F., Baillon, M., Canellas, C., Franchisteguy, L., and Morel, S.: Analysis of Near-Surface Atmospheric Variables: Validation of the SAFRAN Analysis over France, J. Appl. Meteorol. Clim., 47, 92-107, 2008.

Refsgaard, J. C.: Parameterisation, calibration and validation of distributed hydrological models, J. Hydrol., 198, 69-97, 1997.

Ritter, B. and Geleyn, J. F.: A Comprehensive Radiation Scheme for Numerical Weather Prediction Models with Potential Applications in Climate Simulations, Mon. Weather Rev., 120, 303325, 1992.

Stieglitz, M., Rind, D., Famiglietti, J., and Rosenzweig, C.: An Efficient Approach to Modeling the Topographic Control of Surface Hydrology for Regional and Global Climate Modeling, J. Climate, 10, 118-137, 1997.
Warrach, K., Stieglitz, M., Mengelkamp, H. T., and Raschke, E.: Advantages of a Topographically Controlled Runoff Simulation in a Soil-Vegetation-Atmosphere Transfer Model, J. Hydrometeorol., 3, 131-148, 2002.

Weglarczyk, S.: The interdependence and applicability of some statistical quality measures for hydrological models, J. Hydrol., 206, 98-103, 1998.

Wood, E. F., Lettenmaier, D. P., and Zartarian, V. G.: A land-surface hydrology parametrization with subgrid variability for general circulation models, J. Geophys. Res., 97, 2717-2728, 1992.

Xie, Z. and Yuan, F.: A parameter estimation scheme of the land surface model VIC using the MOPEX databases, IAHS Publication, 307, 169-179, 2006.

Young, I. M., Blanchart, E., Chenu, C., Dangerfield, M., Fragoso, C., Grimaldi, M., Ingram, J., and Monrozier, L. J.: The interaction of soil biota and soil structure under global change, Glob. Change Biol., 4, 703-712, 1998.

Zhao, R. J.: The Xinanjiang model applied in China, J. Hydrol., 135, 371-381, 1992. 